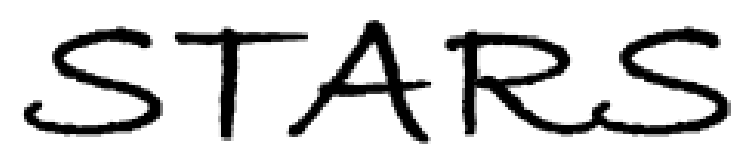

University of Central Florida

STARS

Electronic Theses and Dissertations, 2004-2019

2007

\title{
Valuing Volunteers: The Impact Of Volunteerism On Hospital Performance
}

Renee Brent Hotchkiss

University of Central Florida

Part of the Public Affairs Commons

Find similar works at: https://stars.library.ucf.edu/etd

University of Central Florida Libraries http://library.ucf.edu

This Doctoral Dissertation (Open Access) is brought to you for free and open access by STARS. It has been accepted for inclusion in Electronic Theses and Dissertations, 2004-2019 by an authorized administrator of STARS. For more information, please contact STARS@ucf.edu.

\section{STARS Citation}

Hotchkiss, Renee Brent, "Valuing Volunteers: The Impact Of Volunteerism On Hospital Performance" (2007). Electronic Theses and Dissertations, 2004-2019. 3210.

https://stars.library.ucf.edu/etd/3210

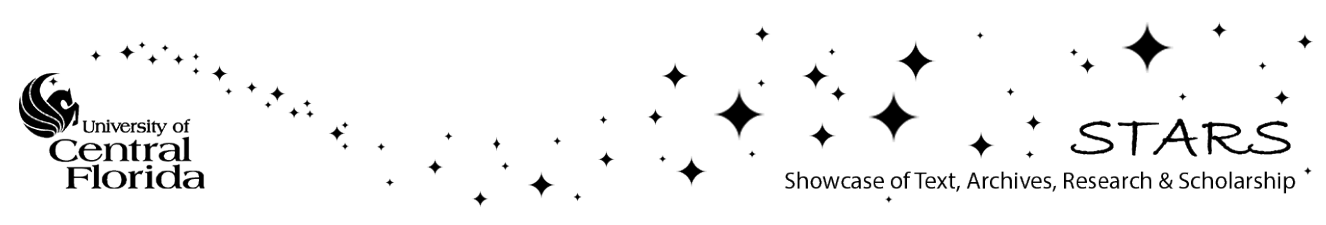


VALUING VOLUNTEERS:

THE IMPACT OF VOLUNTEERISM ON HOSPITAL PERFORMANCE

by

\section{RENEE HOTCHKISS}

B.S. University of Central Florida, 2002

M.S. University of Central Florida, 2004

A dissertation submitted in partial fulfillment of the requirements

for the degree of Doctor of Philosophy in Public Affairs

in the College of Health and Public Affairs

at the University of Central Florida

Orlando, Florida

Fall Term

2007

Major Advisor: Myron D. Fottler 
(C) 2007 Renee Hotchkiss 


\begin{abstract}
Volunteers have been present in healthcare settings for centuries, however there is little empirical evidence supporting the impact that volunteers make on hospital performance. Since the 1990s, hospitals in the United States have had a great deal of pressure to produce high quality care at minimum expense. With the pressures of managed care and accrediting agencies, the benefits of using volunteers in a hospital setting are multiplied. Furthermore, as the population of the United States grows and the aging population creates more healthcare needs, the need for volunteers in hospitals may increase.

This study utilized multiple regression analysis to explore the belief that the volunteer workforce is cost effective and can greatly enhance quality in a hospital setting. Hospitals throughout the state of Florida were invited to participate in the study by completing a brief questionnaire about their volunteer programs. Performance indicators of profit margin, volunteer cost savings, and patient satisfaction scores were analyzed using American Hospital Association and Agency for Health Care Administration data sets along with data obtained from the questionnaire. Results indicate that the use of volunteers offer significant cost savings to hospitals. Furthermore, the assignment of volunteers in patient settings can enhance a hospital's patient satisfaction scores. It also suggests that there is a need to further explore the impact of volunteers on other performance measures. Future research opportunities and policy recommendations are suggested.
\end{abstract}


I wish to dedicate this dissertation to my parents Fred and Michele Brent and my husband Travis. Throughout my life my parents have encouraged me to dream and have taught me that with hard work, dedication, and perseverance anything is possible. For the last year my husband has stood by my side through all the joys and frustrations of this effort, constantly supporting my goal. Without their continuous support, kind words, and generous acts of encouragement this dream would never have become a reality. 


\section{ACKNOWLEDGMENTS}

I want to give special thanks to Dr. Myron Fottler, chair of my doctoral committee, for his guidance, expertise, and continued support. I am grateful to have been mentored by someone that was so able and willing to impart valuable knowledge and essential life lessons.

Special thanks also to Dr. Ning Zhang who taught me the significance of statistics and led me throughout my data analysis. Dr. Zhang's knowledge of statistics is beyond impressive and I am thankful to have received assistance from such a scholar.

My other committee members Dr. Lynn Unruh and Dr. Mary Ann Feldheim, have given me their time and effort to help me produce this dissertation. They have each supported me through difficulties and have encouraged me throughout. Their efforts and dedication are much appreciated.

I would also like to thank my family for their support in the pursuit of my dreams. My parents have always encouraged my undertakings and have always been there to offer a kind ear, a warm embrace, and all their love. Since the days of our youth, my sister has forever challenged me and her support in this effort has pushed me to new levels. Special thanks to each of them for teaching me to never give up and providing my foundation.

Lastly, I would like to thank my devoted husband and best friend. When we met the thought of a PhD and a dissertation had not even crossed my mind. Yet, nearly six years later I have accomplished this goal. Throughout the process, he has supported me and has always encouraged me through the good and bad. The vision of our future together has been the driving force of this pursuit. 


\section{TABLE OF CONTENTS}

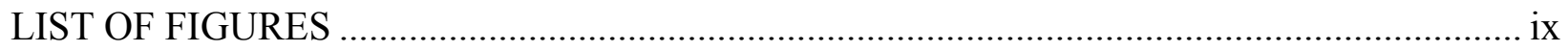

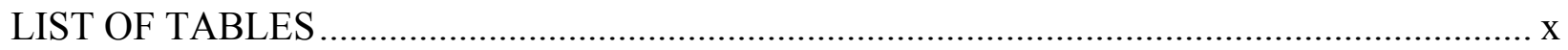

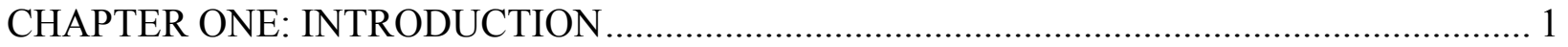

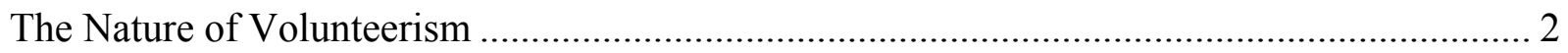

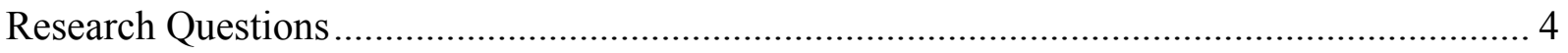

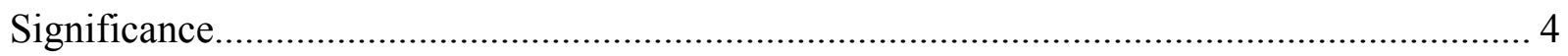

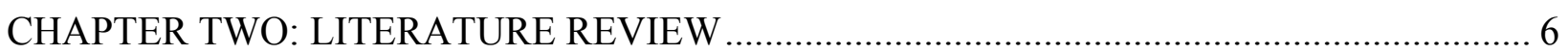

Impact of Volunteerism on Profit Margin and Volunteer Cost Savings...................................... 6

Impact of Volunteerism on Patient Satisfaction and Patient Safety ........................................ 15

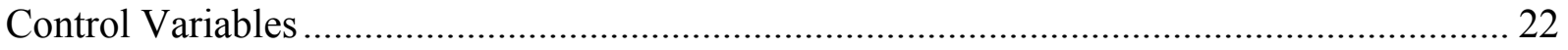

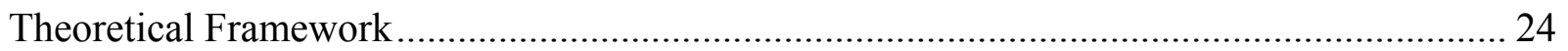

Research Questions and Hypotheses ............................................................................. 28

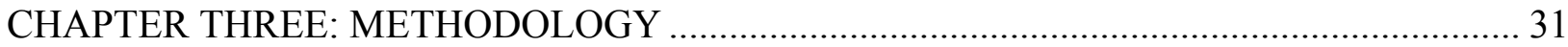

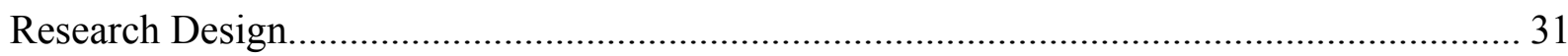

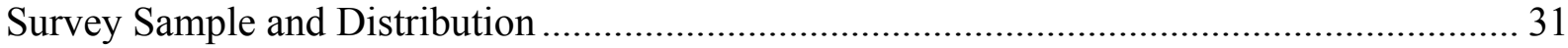

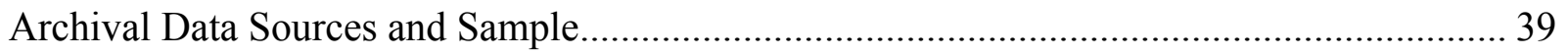

Instrumentation and Measures …………………….......................................................... 41

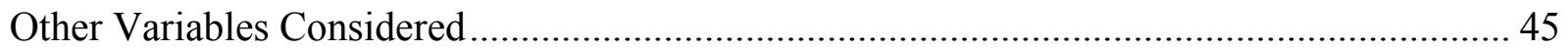

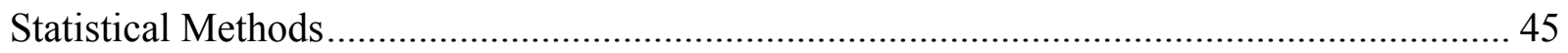

Priori Power Analysis ......................................................................................................... 47

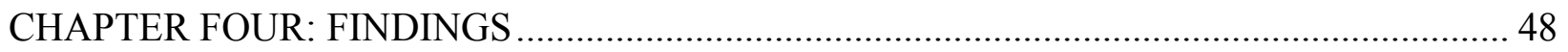




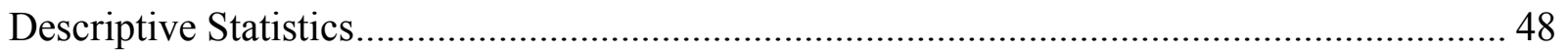

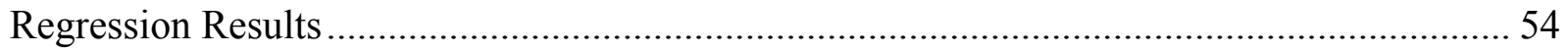

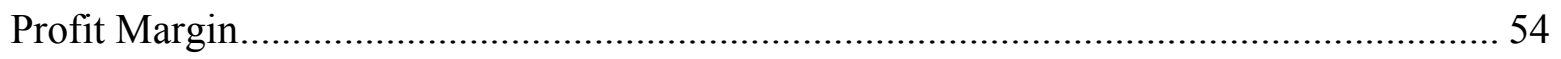

Volunteer Cost Savings............................................................................................... 57

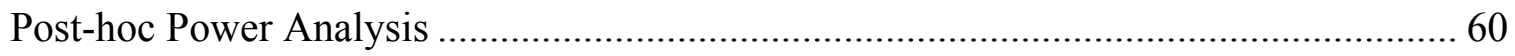

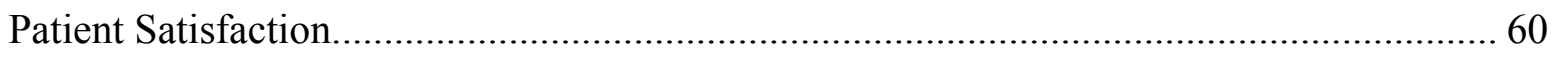

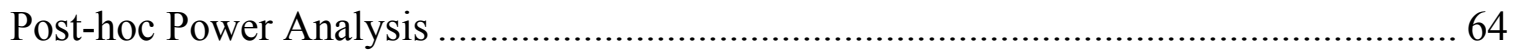

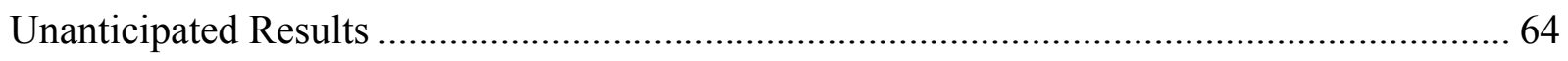

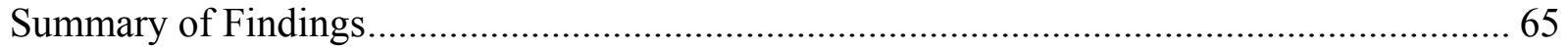

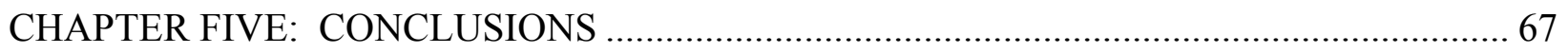

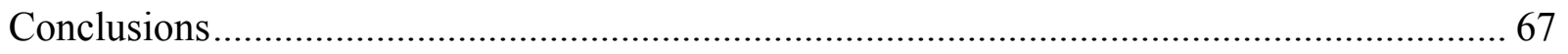

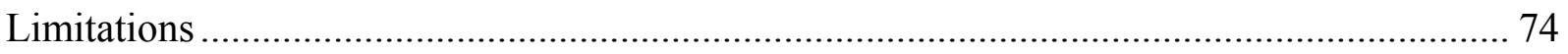

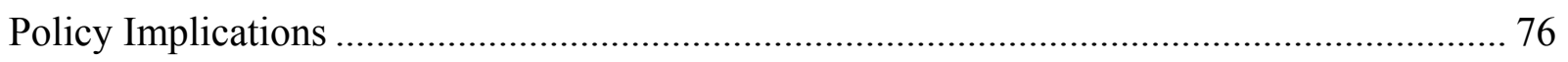

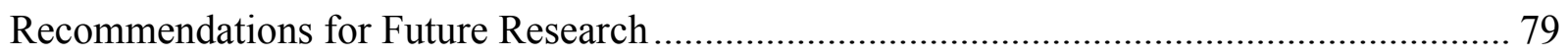

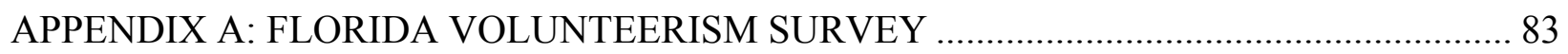

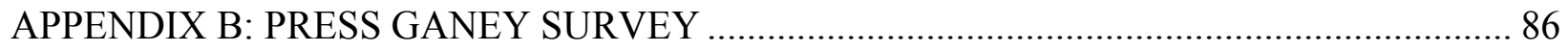

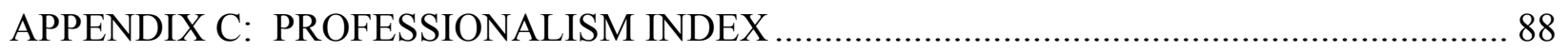

APPENDIX D: BOX PLOT OF COOK'S DISTANCE FOR PROFIT MARGIN ......................... 90

APPENDIX E: BOX PLOT OF COOK'S DISTANCE FOR VOLUNTEER COST SAVINGS 92 APPENDIX F: BOX PLOT OF COOK'S DISTANCE FOR PATIENT SATISFACTION ....... 94 APPENDIX G: NORMALITY OF PROFIT MARGIN REGRESSION EQUATION ................ 96 APPENDIX H: NORMALITY OF VOLUNTEER COST SAVINGS REGRESSION

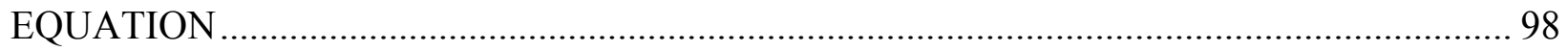


APPENDIX I: NORMALITY OF PATIENT SATISFACTION REGRESSION EQUATION 100

APPENDIX J: IRB APPROVAL LETTER ...................................................................... 102

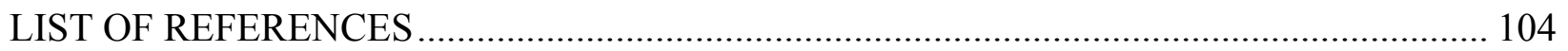




\section{LIST OF FIGURES}

Figure 1 Conceptual Framework of All Variables............................................................... 28 


\section{LIST OF TABLES}

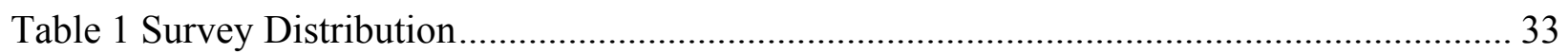

Table 2 Descriptive Statistics for Hospitals within Florida Compared to Hospitals that were Sent

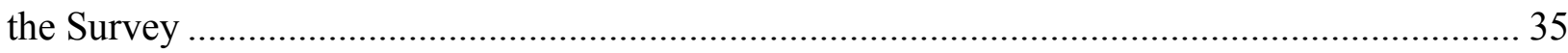

Table 3 Descriptive Statistics for Hospitals that were sent the survey Compared to Survey

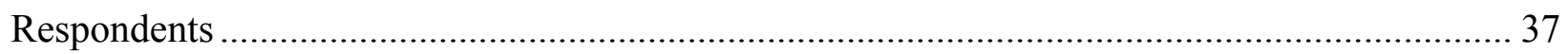

Table 4 Descriptive Statistics for Hospitals within Florida Compared to Survey Respondents .. 39

Table 5 Operational Definitions of All Variables in This Study ................................................. 44

Table 6 Descriptive Statistics for All Variables in this Study ................................................... 51

Table 7 Correlation Matrix for All Variables in this Study ........................................................ 53

Table 8 Coefficients, ANOVA, and Model Summary of the Regression for Profit Margin ........ 56

Table 9 Coefficients, ANOVA, and Model Summary of the Regression for Volunteer Cost

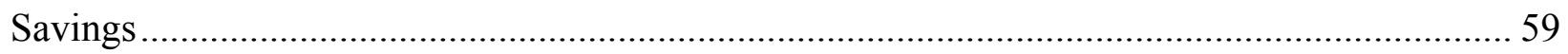

Table 10 Post-hoc Power Analysis of Volunteer Cost Savings Regression ................................. 60

Table 11 Coefficients, ANOVA, and Model Summary of the Regression for Patient Satisfaction

Table 12 Post-hoc Power Analysis of Patient Satisfaction Regression ........................................ 64

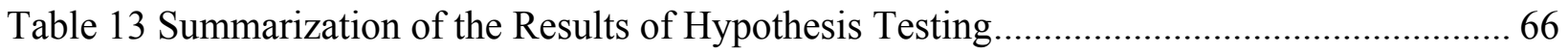




\section{CHAPTER ONE: INTRODUCTION}

For decades American organizations have captured the use of volunteers in multiple aspects of their undertakings. This type of non-profit work is a distinctive feature of American values. It is estimated that sixteen to fifty-five percent of all Americans between the ages of eighteen and sixty-four are volunteering their time (Zweigenhaft, Armstrong, Quintis, \& Riddick, 1996). In addition to organizational settings, volunteers have been involved in healthcare settings and for many years have been a formidable presence in hospitals.

Since the 1990s, hospitals in the United States have had a great deal of pressure to produce high quality care at minimum expense. This pressure is primarily the result of managed care organizations and their ability to control hospital reimbursements, thus indirectly influencing a hospital's profit margin. Furthermore, the implementation of utilization review in many managed care settings has motivated hospitals to use minimal resources in the provision of care. With these developments, the benefits of using volunteers in a hospital setting are multiplied. The volunteer workforce is cost effective and can greatly enhance quality in a hospital setting (Handy \& Srinivasan, 2004).

As the population of the United States grows and the aging population creates more healthcare needs, the need for volunteers in hospitals may increase. The American healthcare system relies upon volunteers to perform numerous tasks and will most likely continue to do so as the healthcare needs of the population grow. This paper will explore the issue of volunteerism and its impact on hospital performance. 
The Nature of Volunteerism

Volunteerism is commonly defined as "long-term, planned, prosocial behaviors that benefit strangers and occur in an organizational setting” (Penner, 2002, 448). In more detail, volunteerism includes four distinct features; longevity, planfulness, nonobligatory helping, and organizational context. Longevity is highly related to volunteerism in that multiple studies have shown linkages between volunteering and the desire to volunteer for a long period of time. Moreover, individuals who volunteer plan to do so, and thoughtfully consider their various opportunities to become a volunteer. Additionally, volunteerism involves behaviors directed to assist strangers whom the volunteers themselves are not obligated in any way to assist, but opt to help even though it may not be their responsibility. Finally, studies estimate that most volunteers do so in an organizational setting (Penner, 2002).

The role of the volunteer can greatly vary depending on the type of work being performed. For example, in some instances volunteers are administrators of charity organizations, while in other cases they perform tasks in church settings, deliver meals to people without transportation, work for political campaigns, or visit with patients in healthcare settings. Volunteer work ranges from the informal to the very formal (Zweigenhaft et. al., 1996).

Individuals become volunteers for the good of others. However, in helping others, volunteers may receive benefits themselves. They want to give back to a society that they feel has been very helpful towards them. There are also known to be a multitude of motivating factors for volunteers. Some factors are social, meaning that they build upon interpersonal relationships, a desired outcome for older volunteers. Others are personal in that they provide self-fulfillment. Still others are economic in the sense that they provide networking benefits and work experience 
for younger volunteers. In most instances volunteers are giving towards a cause while also gaining from the experience (Zweigenhatt et. al., 1996).

Organizational characteristics are strongly related to volunteerism. According to Penner (2002), two organizational traits are particularly influential on the level of volunteerism. They are the individual's perceptions or feelings about the way they are treated by the organization, and the organization's reputation and practices. If an individual feels that they are being improperly treated in an organization they are unlikely to commence or continue volunteering with that organization. Likewise, prestigious organizations have been found to be more attractive to potential volunteers (Penner, 2002).

Individuals learn about and become hospital volunteers through various methods. First, many are in some sort of transitional period and seek out volunteering to provide them with social support during a difficult time period. For instance, many hospital volunteers are newly retired or recently widowed. Others learn about the opportunities available for hospital volunteers through other organizations such as their religious organizations or through community clubs. Still others discover the possibility to become volunteers when a relative or friend is being treated at a hospital or even when they themselves are patients (Wymer, 1998). The quality of volunteers can be assessed based on a variety of circumstances. In the study performed by Zweigenhatt, Armstrong, Quintis and Riddick (1996), two factors, dependability and personal impact on the volunteer program were considered indicators of quality. Multiple variables, including age, gender, education, religion, the number of hours worked per month, the amount of time one had been a volunteer, whether the person had previous volunteering experience, and whether the person's parents had been volunteers, were evaluated as positive predictors of these indicators. The study found that older volunteers were 
generally more dependable than younger ones. Furthermore, women volunteers were found to be more dependable than men. The number of hours worked, the gender of the volunteer, and religion were all found to be indicative of the impact made by a volunteer. Women who believed religion to be very important and worked the most hours made the greatest impact as volunteers (Zweigenhaft et. al., 1996).

\section{$\underline{\text { Research Questions }}$}

There is a great deal of pressure on healthcare organizations to keep cost low while providing excellent service. This pressure will only increase over the next decade as the baby boomer generation enters into retirement and experiences greater healthcare needs. Hospital volunteers are seen as a great resource to hospitals; their contributions positively influence the performance of the hospital. However, there is a little empirical evidence to support this claim. The research question to be addressed in this study is: What impact does the level of volunteerism in hospitals relative to the size of the workforce have on various organizational outcomes? This study will contribute to our assessment of the value and impact of volunteers in hospitals. The specific research questions and hypotheses will be presented in Chapter 2 .

\section{$\underline{\text { Significance }}$}

This study will provide empirical evidence as to the value of volunteers. If the study finds that volunteers provide value in terms of financial performance and patient satisfaction then it will support the belief that volunteers are indeed priceless resources to hospitals. It may also illustrate the need to increase and enhance volunteer programs so that the true worth of the 
volunteers can be realized. Furthermore, the empirical evidence provided by this study when shared with current and future volunteers may act as a motivational tool. Finally, this study can guide future policy regarding Federal, state, and local volunteer programs by providing significant insight as to the strengths of volunteerism and suggest methods of enhancing volunteer programs nationwide. 


\title{
CHAPTER TWO: LITERATURE REVIEW
}

\author{
$\underline{\text { Impact of Volunteerism on Profit Margin and Volunteer Cost Savings }}$
}

Volunteers can provide financial benefits to hospitals. In the past, volunteers were primarily used in hospital settings to run gift shops, perform fund-raising activities and assist with patients. However, due to economic pressure from managed care organizations, hospitals need to maximize resources and are exploring new ways to utilize volunteers. They are now working in non-medical service areas, in areas requiring governing responsibilities, and in enhancing fund-raising (Handy, Srinivasan, 2004). For instance, volunteers now serve on boards of directors and advisory boards. These types of volunteers assist in policy making. Others provide direct services through administrative work, advocacy, and fund-raising (Conners, 1995). Thus, the nature of volunteer services has expanded and includes a variety of tasks and duties. At a time when health care costs continue to rise, volunteers offer an opportunity to enhance care without raising costs (Wells, B.L., DePue, J.D, Buehler, C.J., Lasater, T.M., Carleton, R.A., 1990).

Susan Ellis (1999) notes that assigning a dollar value to volunteers is a bit of a controversial topic. Some arguments against doing so suggest that assigning a monetary value to volunteerism may devalue the act of volunteering and "doesn't feel right" (p. 1). Many nonprofits do not keep accurate records making quantification extremely difficult. Opposition from management to include volunteer time in financial reports occurs frequently because they may make the organization appear to be less efficient (Ellis, 1999). Furthermore, benefits from these volunteer programs are often intangible and are therefore difficult to quantify. This argument is also taken by Linda Graff (2001) in the article Be Careful What We Wish For! The 
Cost-Benefit Analysis of Volunteering. Graff (2001) is of the opinion that many cost-benefit analyses of volunteerism fail to account for intangible benefits of volunteers and may hurt volunteer programs. But, as Ellis (1999) suggests, because we live in a world consumed by money, without the assignment of a dollar value, volunteer programs will not get the attention they deserve. She asserts that volunteer value should be calculated based on the actual tasks that they are performing and what those tasks would cost if it were being performed by a paid employee. Using this type of measure it can be demonstrated that volunteerism extends the budget of an organization allowing for greater outcomes without increased spending (Ellis, 1999).

Dordrecht (1978) also discusses the issue of the economic value of volunteer activity. In his study, he provides a definition of economic volunteer service which differs from the traditional definition of volunteer activity. Traditionally, volunteer activity is considered any action that is not paid for excluding school, church or other recreational attendance. On the other hand, economic volunteer service "produces new economic value by applying a conventional economic factor of production" including labor, time, and capital (Dordrecht, 1978, 7). Similar to Ellis (1999) he suggests that volunteer work be valued based on the task being performed. By measuring volunteer hours and determining the market replacement value for their services, an economic value can be determined. However, he also notes that one hour of volunteer time may not be equal to one hour of paid time (Dordrecht, 1978).

In the article Assigning Economic Value to Volunteer Activity (2002), Goulbourne and Embuldeniya developed eight measures that could be used to estimate volunteer value. These eight measures can be further subdivided into the categories of human resource productivity measures, volunteer program efficiency measures, and community support measures. The 
human resource productivity measures and volunteer program efficiency measures are both related to this study and include estimates of the value of volunteer activity, true value added to personnel, full-time year-round job equivalent, percent personnel value extended, organization volunteer investment ratio, and volunteers to paid staff ratio (Goulbourne, Embuldeniya, 2002).

The first human resource productivity measure suggested by Goulbourne and Embuldeniya (2002), the value of volunteer activity, uses a wage rate dollar value to estimate the monetary value of volunteer time. This same type of measurement has been used in other studies including Christian (2007) and Handy and Srinivasan (2004). True value added to personnel assigns a wage rate and benefits to estimate volunteer value (Goulbourne, Embuldeniya, 2002). Each year The Independent Sector releases a new dollar figure similar to the true value added measurement that is globally considered the best estimate of the value of volunteers. This figure is calculated based on an average hourly rate released by the Bureau of Labor Statistics and increasing it by $12 \%$ to include benefits (Kentner, Lange, Reifschneider, Takacs, 2003).

Another measure used by Goulbourne and Embuldeniya (2002), is the full-time yearround job equivalent that converts the number of volunteer hours to the equivalent number of full-time positions. The final human resource productivity measure, percent personnel value extended, demonstrates the degree to which volunteers extend the value of the organization's personnel. It is calculated by adding the value of volunteer donations to the human resource labor cost for the organization and then creating a ratio by dividing it by the value of volunteer donations (Goulbourne, Embuldeniya, 2002). Each of these measures was considered in the development of a volunteerism measure for this study. Furthermore, the volunteer cost savings dependent variable utilized a combination of the value of volunteer activity and the human resource productivity measures. 
The volunteer program efficiency measures utilized by Goulbourne and Embuldeniya (2002) include organization volunteer investment ratio which is used to determine the organization's return on its investments into the volunteer program. It is calculated by dividing the estimated value of volunteer activity by the total amount that the organization spends on the volunteer program. A second volunteer program efficiency measure is the volunteer to paid staff ratio. It divides the total number of volunteers by the total number of full-time and part-time staff to determine a ratio (Goulbourne, Embuldeniya, 2002). Again, both of these measures were considered as options for this study. In fact, the volunteerism measure, a ratio of volunteer hours/FTE hours, is a slight variation of the volunteer to paid staff ratio in that it utilizes hours rather than numbers.

Other measures related to community support include volunteer capital contribution and community investment ratio. The volunteer capital contribution calculates the out of pocket expenses that volunteers incur that are not claimed as in-kind donations. The community investment ratio compares the amount of money that is invested into the volunteer program to the amount of time volunteered (Goulbourne, Embuldeniya, 2002).

The 2001 telephone survey study from the Independent Sector, Giving and Volunteering in the United States, found that fifty four percent of adults over 21 years old volunteered in 2000. This is estimated to be approximately 83.9 million individuals that have participating in a volunteer program. Likewise, these volunteers gave over 15.5 billion hours of their time that same year. Over forty percent of these volunteers also provided charitable donations to organizations (The Independent Sector, 2001).

In 2003 a cost benefit analysis of volunteering was performed to assess volunteerism in the United States as a whole. This study was significant because prior to it, few studies had 
performed cost benefit analyses on volunteerism. Using data from the 2002 Current Population Survey this study was able to identify characteristics of volunteerism in the United States. It was found that on average, volunteers contributed 52 hours of time per year. The primary costs to the volunteer programs themselves are those costs related to planning, implementing, and managing the program. The volunteer also incurs costs such as travel expenses and other out of pocket expenses in addition to the opportunity cost of the time given. There are also indirect costs related to liability issues at both the program and individual volunteer level (Kentner et. al., 2003).

Kentner et. al. (2003) also found extensive benefits associated with volunteerism. These include benefits to the organization and to the volunteer. The organization utilizing volunteers will experience the benefit of more work done for less money and the community will benefit from the work being performed by volunteers. Furthermore, volunteer managers will be extending their skill set by gaining such management experience. Indirect benefits to the organization include enhanced exposure to the public, positive public relations, increased partnership and networking opportunities, increased organizational accountability, and a fresh outlook from the volunteer perspective. Volunteers are likely to experience an improved social outlook. Their self worth is typically enhanced and their social opportunities are increased. Furthermore, health benefits have been found to be associated with volunteering (Kentner et. al., 2003). In addition to these benefits, the following studies have found empirical evidence of the value of volunteerism.

In his case study using the volunteer referral center of Toronto, Dordrecht (1978) found that there is a large percentage of economic volunteer service and health and rehabilitation services with hospitals and other large organizations dominating the grouping. In fact, general 
hospitals utilized nearly $9 \%$ of volunteer referred by the center, while other health and rehabilitation services utilized an additional $24 \%$ of volunteer referred by the center. He also found that nearly $58 \%$ of volunteer time is spent in six task areas including supervision and friendly visiting, parole counsel, childcare, clerical, and driving. With the exception of parole counsel, each of these is performed across the spectrum of organizational settings including hospitals. Using 1971 mean equivalent market values for these task areas Dordrecht (1978) found that the average value of annual volunteer service was $\$ 830$ per volunteer. As an aggregate, the 5,334 volunteers that were referred through the Metro Toronto Volunteer Centre provided services that were valued at the 1976 inflated rate of nearly $\$ 5,334,000$ (Dordrecht, 1978). This study demonstrates the value of volunteerism over 30 years ago was above $\$ 5$ million in Toronto. Considering that this study was decades ago, the further inflation of that value is likely to be substantial.

A recent study performed by Michael Christian (2007) utilized a calculation similar to the value of volunteer activity estimate supported by Goulbourne and Embuldeniya (2002). He used data from the American Time Use Survey to "account for home and volunteer production of health-related services in the United States" (p. 78). The home and volunteer health sector accounts for $\$ 314$ billion dollars of output with public health volunteer activities accounting for $\$ 2.7$ billion. According to his study, $14 \%$ of the total health sector market output is produced by home and volunteer activities (Christian, 2007).

Christian (2007) developed this figure by looking at the amount of time spent on public health volunteer activities and other home health activities. Volunteer activities included the donation of blood and the provision of services as a medical volunteer. Nearly 296 million hours were accounted for as public health volunteer activities. Using an hourly wage of $\$ 9.18$, or the 
wage of home health aides, he determined that public health volunteer activities had a monetary value of $\$ 2.7$ billion (Christian, 2007).

Similarly, Handy and Srinivasan (2004) determined the average value of volunteer time at the hospital level. In their study, the average number of volunteer hours in one year at an average hospital facility of 468 beds is 70,515 , a number equivalent to forty-two full time employees. If these volunteers were replaced by forty-two employees at the average reported clerical salary of just over $\$ 30,000$, it would cost the hospital approximately $\$ 1,260,000$ a year. Moreover, that amount is only accurate if the forty-two employees share the same skill set as the replaced volunteers; otherwise more hires would be necessary (Handy and Srinivasan, 2004). This type of calculation can be used in this study to estimate volunteer cost savings.

Additionally, the findings of Handy and Srinivasan (2004) should be considered a strong indicator of the significant return on investment volunteers provide to individual hospitals. Volunteers were found to provide over 70,000 hours a year at an annual opportunity costs greater than one million. Likewise, multiple benefits of using volunteers in hospital settings are unable to be quantified, but expected to be of significant value. These benefits include increased patient interaction, enhancements in the hospital environment, assistance to the hospital employees, and others. Benefits of this sort decrease the workload of paid employees and greatly enhance the quality of care provided (Handy and Srinivasan, 2004).

In 2006, Help the Hospices sent a survey to all UK hospices to determine the value of volunteers in hospice settings. Again, this study notes that not all volunteer contributions can be quantified. However, like Handy and Srinivasan (2004), they determine volunteer value by calculating the cost of replacing volunteers with paid employees. Their calculation of volunteer 
value uses a mean replacement value and adds an overhead of 30\%. Fifty-nine hospices participated in the study at a response rate of $28 \%$ (Help the Hospices, 2006).

The results of Help the Hospices (2006) study demonstrated significant value with volunteerism in all UK hospices being worth $£ 112 \mathrm{~m}$ or nearly $\$ 230$ million at the current exchange rate. In addition, the study found that over half of volunteerism efforts take place in the fundraising aspect of hospice organizations. If these fundraising volunteers were paid for the work that they do the expenses for fundraising would be $150 \%$ greater. Over $35 \%$ of volunteerism in hospices was found to occur in care and administrative settings. Also, if care and administrative volunteers were paid for their work the expenses in these areas would increase by $110 \%$. Furthermore, if all volunteer workers were replaced by paid employees, the expenses to the hospices would increase by nearly a quarter (Help the Hospices, 2006). The sizable increase in expenses demonstrated by these results illustrate the impact of volunteerism on volunteer cost savings.

In addition to determining the increase in expenses a hospice would incur if volunteers were replaced by paid employees, the Help the Hospice (2006) study calculated a measure they called a volunteer investment and value audit. This measure was divided the individual hospices volunteer value by all of the costs related to having a volunteer program. It was used to demonstrate the efficiency of volunteer programs in each hospice. The results showed that for every $£ 1$ spent on volunteers there was a return of $£ 11$ (Help the Hospice, 2006). Gaskin (n.d.), utilized this same calculation to determine that in England, the Netherlands, and Denmark, the overall return on the investment of volunteers is between $\$ 2.05$ and $\$ 21.24$ for every $\$ 1.57$ spent. Again, this shows the impact that volunteerism can make on organizational performance including profit margin and volunteer cost savings. 
Based on this literature, it is expected that the degree of volunteerism will increase volunteer cost savings in the form of number of volunteer hours multiplied by an average hourly rate minus the associated costs, which include the combined salaries of paid volunteer services staff and the volunteer program's operating budget. This calculation is similar to that used in the volunteer investment and value audit measure developed by Help the Hospice (2006). Hospitals with a large number of volunteers and hospitals that are provided with large amounts of volunteer hours are less likely to spend on new hires, especially for temporary and part-time employees (Handy and Srinivasan, 2004). Furthermore, the number of full time hours may be lessened due to the significant impact made by the volunteers within these organizations.

Some of the costs incurred by the use of a volunteer workforce include recruitment costs, administrative and supervisory costs, liability expenses, and recognition (Handy, Srinivasan, 2005). However, these expenses can be difficult to quantify. By calculating an estimate of the time spent for these activities and the salaries paid to volunteer coordinators and trainers Handy and Srinivasan (2004) approximate this cost to be $\$ 185,405$ annually with an average bed size of 468. Additionally, the foregone opportunity costs, transportation costs, and other out of pocket expenses of the volunteer should be considered. According to Handy and Srinivasan (2005), the volunteer administration budget can be used as a proxy for volunteer costs. This budget includes the salaries of volunteer managers and paid staff dedicated to volunteer services (Handy, Srinivasan, 2005). Previous studies have shown that volunteerism decreases when the cost of volunteer services increase (Govekar, 2002). Despite these known cost areas, the benefits of using a volunteer workforce, based on the calculation of the value of volunteer time (hours multiplied by average wage rate) are estimated to outweigh the expenses (Handy and Srinivasan, 2004). 
Another rarely perceived return on investment is that of external donations provided to not-for-profit hospitals by prior volunteers. Many volunteers become deeply attached to the organizations in which they spend numerous hours over several years of their life. Those who fondly remember their experiences are highly likely to be motivated to offer financial aid to organizations in order to assure its future within their community even when they are no longer able to offer their services as a volunteer. Moreover, current volunteers in non-profit settings are likely contributors to annual campaigns. External funds are also a possibility when influential members of the community, with access to financial resources, are offered substantial volunteer roles. Yet, in order for the possibility of long term donations to be realized it is necessary and important for the hospital to remain in touch with former volunteers, a task that is rarely performed (Pidgeon, 1998).

Impact of Volunteerism on Patient Satisfaction and Patient Safety

Hospital volunteers contribute multiple hours of unpaid service. In doing so, it is believed they add to the perceived quality of a hospital by contributing to the happiness and comfort of patients, their families and visitors. They add a human touch to the technical aspect of care. By supplementing existing staff, they relieve the workload of medical and technical employees. Wells et. al. (1990), notes that volunteers are especially helpful when professionals are unavailable or staff is shorthanded. This benefit primarily arises because of the volunteer's ability to relieve paid employees of routine tasks so that they can better focus their efforts on caring for those individuals in need of their services (Wells et. al., 1990). 
In his book Leprosy, Racism, and Public Health, Zachary Gussow (1989), discusses the historical role of volunteerism in the aide of lepers. As early as the 1870's mission societies were assisting in the care of lepers. This later developed into volunteer work in the medical treatment of lepers. In many instances, lepers were outcast and isolated from society and, were it not for those acts of volunteerism, they would have been left uncared for (Gussow, 1989). In more recent years, leprosy has become less of an isolating disease, however throughout history the effect of volunteerism on the care of these individuals is substantial. The impact of volunteers on leprosy can be compared to their impact on the care of HIV and AIDS patients during the early onset of the AIDS epidemic. Gussow's (1989) works highlight the impact that volunteerism has had on patient care for centuries and suggests that volunteers frequently offer support when no one else will.

In examining hospitals using a professionally managed volunteer program, Handy and Srinivasan (2004), found the following seven items to be those task areas that are most likely to use volunteers:

- Accompanying patients on outings

- Providing companionship and friendly visiting on a one-to-one basis

- Providing support to patients and families in waiting rooms, clinics, support groups, and so forth

- Assisting with recreational and social programs

- Shopping and doing errands

- Taking patients from one facility to another within the site

- Assisting with administrative functions 
Each of these items, with the exception of administrative functions, involves direct interaction with patients, potentially promoting quality and reducing workload. Additionally, hospital volunteers assist in clerical duties, community and public relations, and sometimes serve on committees and boards (Handy and Srinivasan, 2004).

According to Connors (1995), volunteers fill many gaps left unfilled by hospital employees. This may be especially true in times of staffing shortages such as nursing shortages. Contemporary volunteers possess skills such as computer, accounting, engineering, and legal skills that can enhance the operations of a hospital. Furthermore, they are attentive to patients and clients in that they have the time to offer individualized attention while employees may not. Thus, it is believed that the humanization of services offered by volunteers adds to the quality of the hospital and enhances patient satisfaction (Connors, 1995).

Most patients do not recognize a distinction between volunteers and paid staffers. Therefore, they both make an impact on the customer experience. Volunteers should be given the same customer service training as staff members and should also be evaluated based on their customer service skills. As end-users of many hospital tools, volunteers should be encouraged to give suggestions for improvement (Jones, 2002). Further, using volunteers in more patient settings allows volunteers, and therefore hospitals, to quickly recognize areas that could benefit from improvements. In that sense, volunteers can act as consumer focus groups and speak on behalf of patients (Larson, 2004).

In 2004 the Wales Council for Voluntary Action found that volunteers "increase capacity and resource within the health services" (Jones, 2004, 5). In their study, over $60 \%$ of respondents in health settings found that volunteers improved services that they provide. In most cases these respondents felt that volunteers supported staff and in some cases they felt that 
volunteers added something extra to the services being provided. Specific examples found by this study included volunteers who befriend patients thereby adding to the overall patient experience (Jones, 2004).

One study on the impact of volunteer ombudsmen in nursing homes found that volunteers neither increased nor decreased the rate of patient complaints but rather, volunteers ward off problems. Their presence created a sense of greater accountability for paid employees and as an extra eye in the workplace; they were able to watch out for issues related to patient satisfaction and safety. In doing so, the health of the patients was expected to improve and therefore these volunteers played an important role in the patient experience (Allen, 2006).

Similarly, hospice volunteers have been found to make a significant contribution to the experiences of hospice patients. In providing spiritual and physical care for the dying, such volunteers provide notable comfort to hospice patients and their families. They often assist the patient's families in the grieving process. In a case study by Downe-Wamboldt and Ellerton (1986), hospice volunteers gave $58 \%$ of their time to listening and responding to both patients and their families. Socialization with patients accounted for $13 \%$ of the volunteer time, with physical comfort measures accounting for $10 \%$ of their time and spiritual comfort an additional 6\%. Many patients reported that they were more comfortable discussing their fears and concerns with a volunteer than with a doctor or nurse. In many cases the patients fears involved loneliness or depression rather than pain and the volunteer's presence helped to diminish these concerns (Downe-Wamboldt and Ellerton, 1986).

Another case study on the impact of volunteer liaisons in the emergency room of CGH Medical Center in Illinois found that volunteers greatly enhanced the patient experience (Wolford, 1995). The duties of the volunteer liaisons included "monitoring the lobby, visiting 
with relatives, serving coffee, spending time with children, and providing families with updates on the status of their loved ones" (p. 18). They also interacted with the patients by checking on them regularly and providing non-medical assistance. A year after its initial implementation the volunteer liaison program was evaluated. The medical staff in the emergency department ranked the program at 4.18 out of 5 . These employees found the volunteers to be helpful in assisting with non-patient related activities, such as paperwork, putting charts together, and folding linens, as well as patient related activities (Wolford, 1995). The assistance in non-patient related activities provided by the volunteers is likely to have allowed the staff to better focus their efforts on the patient.

In addition to the non-patient related assistance that volunteer liaisons provided to $\mathrm{CGH}$ Medical Center, Wolford (1995), found that these volunteers were a great assistance to patient duties such as retrieving blankets, offering water, communicating with friends and family members, and others. By continuously updating the patient's loved ones with their status, volunteer liaisons also assisted in controlling traffic in the emergency department because friends and family members made fewer unnecessary visits when they were informed. Likewise, the emergency department registration staff ranked the program at a 5 out of 5 , stating that the volunteer's assistance in escorting patients and talking with family members were the most helpful duties that the program offered. While the volunteer liaison program was initially started as a cost savings measure (and in fact saved CGH Medical Center $\$ 17,064$ its first year, not including benefits) the end result proved to be much more valuable - a substantial impact on the experience of patients and their loved ones (Wolford, 1995).

A new concern of hospitals is that of disaster preparedness. Following the incidence of September 11th, 2001, many hospitals began to reassess their disaster plans. Few had considered 
the enormous impact that their volunteers could have in the case of a disaster. Including volunteers in disaster plans is another technique that will maximize their usefulness. According to David Baltzer, a member of the AHA Board of Director's Committee on Volunteers, in the event that a disaster occurs, volunteers can assist with emergency childcare centers, handout food and drinks, and be a part of the on-call labor pool (Baisden, 2001).

While there are few studies demonstrating empirical evidence of the relationship between volunteer staff and patient satisfaction, there is substantial evidence of a relationship between the presence of other staff and patient satisfaction. There is particularly strong evidence supporting a relationship between nursing staffing and patient satisfaction (Schmidt, 2004). Thus, it can be assumed that similar links exist between other staff, including volunteers, and the indicators of patient satisfaction.

A number of studies provide evidence in regards to the linkage between nurse staffing and patient safety. Akinci and Krolikowski (2005) studied this association within nursing homes. They found that, as nursing hours per patient days decreased, the number of citations against the nursing home increased. This relationship held true for all types of nurses including RN's and CNA's. Furthermore, an inverse relationship between RN hours and quality of care deficiencies was confirmed by this study.

A second study testing the relationship between nursing hours at a nursing home and six quality indicator scores including physical restraints, weight loss, incontinence, late loss activities of daily living decline, stages 1 to 4 of pressure ulcers, and problem behaviors towards others reported similar findings (Bostick, 2004). This particular study found an inverse relationship between $\mathrm{RN}$ hours and the prevalence of pressure ulcers in residents and a positive relationship between LPN hours and ADL decline. Weech-Maldonado, Meret-Hanke, Neff, and 
Mor (2004) performed a study very similar to Bostick (2004) and confirmed the results by verifying the hypothesis that a higher $\mathrm{RN}$ staffing mix would positively affect quality of care outcomes.

A thorough literature review along with key informant interviews performed by Lankshear, Sheldon, and Maynard (2005) provide greater evidence of the association between nurse staffing and patient outcomes in hospitals. In this review, 22 of 61 identified studies were discussed in detail and each of them found a significant relationship between nurse staffing and patient outcomes. For instance, a greater number of $\mathrm{RN}$ hours resulted in fewer medication errors, patient falls, pneumonia, failure to rescue, shock, upper GI infections, urinary tract infections, pressure ulcers, and cardiac arrest. Higher nurse staffing ratios also resulted in shorter lengths of stay and reduced mortality rates.

Most recently, in 2006, Needleman, Buerhaus, Stewart, Zelevinsky, and Mattke discussed the issue of nurse staffing in relation to cost and quality in hospitals. Their findings suggest that an increase in nurse staffing reduced adverse outcomes. Adverse outcomes included increased length of stay, urinary tract infections, hospital acquired pneumonia, shock/cardiac arrest, upper GI bleed, and failure to rescue. They conclude that hospitals should increase their proportion of RNs without changing the number of licensed hours to enhance patient outcomes at the lowest cost (Needleman et. al., 2006).

Schmidt (2004) explores the nurse staffing, patient safety, and patient satisfaction issue with the overall hospital experience. In addition to agreeing with previous studies about the evident association between nurse staffing and patient safety, this study suggests a direct relation between the patient's perception of nursing care and patient satisfaction. This linkage provides 
evidence that patient satisfaction is positively influenced by staffing and thus could be influenced by volunteer staff.

Since the above studies show the critical importance of nurse staffing for various dimensions or organizational performance, it is not unreasonable to expect a similar relationship of volunteerism to these outcomes although empirical research is sparse. This is the research gap we expect the present study to fill.

\section{$\underline{\text { Control Variables }}$}

The variables of bed size, RN hours/FTE hours, system, ownership, and teaching status have been selected to be used as control variables for this study based on previous research. Bed size, whether the hospital is part of a larger system, and its ownership (non-profit/for-profit), and teaching status are important characteristics of the hospital itself. RN hours/FTE hours is an important measure expressing the level of nurse staffing to overall staffing. Similar to the hospital characteristics, this staffing characteristic is expected to influence the performance of a hospital.

Previous research has found bed size to be positively related to various organizational outcomes studied (Lankshear, Sheldon, \& Maynard, 2005). Numerous other studies including Aiken, Clarke, Sloane, Sochalski, \& Silber (2002) and Lake \& Friese (2006) have controlled for this variable. It is expected that size will impact the performance of a hospital in that larger hospitals have greater profit potential.

Similarly, system, ownership, and teaching status are hospital characteristics that may influence the hospital's performance. A hospital is considered a part of a system if there are two 
or more hospitals or health providers that have vertically, horizontally, or virtually integrated (Fottler \& Malvey, 2003). A hospital that is part of a larger system may have a greater number of resources available at their disposal and thus may perform at higher levels (Lankshear et. al., 2005).

In much the same way, a hospital's status, as for profit or not-for-profit, may influence many of their everyday operations and is believed to positively affect several performance measures (Lankshear et. al., 2005). Teaching status may also positively influence performance because it is believed that teaching hospitals may attract a more experienced group of employees. The intensity of teaching activity has been shown to positively impact patient outcomes, such as lower hospital mortality rates, in previous studies (Aiken et. al., 2002).

$\mathrm{RN}$ hours is a staff characteristic found to be positively related to profit margin, and patient satisfaction (Lankshear et. al., 2005). Nurse staffing has been theorized to influence patient outcomes both directly and indirectly. For instance, more registered nurses per overall staffing should result in better patient outcomes and, therefore, enhance patient satisfaction (Lake, 1999).

In a recent study analyzing nursing and hospital characteristics, hospital bed size, teaching status, and number of full time equivalent RNs per bed were utilized as control variables where the dependent variable was patient outcomes (Lake \& Friese, 2006). Many of these studies also adjusted for hospital characteristics such as ownership, mergers and teaching status because they relate to healthcare and hospital outcomes (Lankshear et. al., 2005). It is necessary to control for these hospital and staffing characteristics because they may impact the dependent variables of profit margin, volunteer cost savings, and patient satisfaction. Their selection was based upon previous studies and the literature. 


\section{Theoretical Framework}

Three frameworks are related to this study. They include organizational performance theory, production theory, and Donabedian structure-process-outcome theory. The first framework, organizational performance can be defined in terms of four interrelated goals. The first and second relate to the goods or services produced by the organization. They are productivity and efficiency. Our dependent variables of profit margin and volunteer cost savings are highly related to these objectives. They both involve analyzing the use of inputs such as dollars, resources, labor, and other capital. In our case, volunteerism is an important input which influences the productivity and efficiency of the hospitals. The definition of productivity is the ratio of outputs to inputs. A greater level of outputs for a smaller level of inputs results in high productivity. Thus, a high number of volunteers or volunteer hours should increase the productivity of the organization. Efficiency is defined as the cost per unit of output (Flood, Shortell, and Scott, 1997). Volunteers provide their services at little or no cost while enhancing the output of the organization. Therefore, they are an efficient source of labor.

The third and fourth goals of organizational performance relate to the organization's ability to successfully meet their objectives. They are organizational effectiveness and cost effectiveness. These objectives may be defined in terms of varying purposes such as motivating for higher performance, acting as evaluation criterion, or defining the organization's overall role. These goals often relate to the values of the stakeholders. For instance, in a hospital, owners, agents or managers may be primarily interested in profit, while other stakeholder groups such as employees and the public have broader performance goals such as quality (Flood et. al., 1997). 
These objectives are highly related with the dependent variable of patient satisfaction. For instance, a goal related to higher performance may be to improve patient satisfaction scores. Production theory provides a useful framework for analyzing the first two dependent variables of this study, profit margin and volunteer cost savings. Production is defined in microeconomics as the conversion of inputs into outputs. In order to create an exchangeable commodity, resources are used. These resources are known as factors of production by economists. There are three widely recognized categories of factors; labor services, capital goods, and land (Maxwell, 1969).

As mentioned earlier, Dordrecht (1978) defines economic volunteer service as influencing production by way of labor services, time, and capital. Volunteers are a unique type of labor service or human capital and, therefore, can be included as an input in the production equation. The dependent variables related to financial performance (profit margin and volunteer cost savings) are both measures that can be utilized to evaluate the production or performance of a service such as health care.

This study relates one specific input, volunteer labor, to the production or performance of a hospital in terms of profit margin, volunteer cost savings, and patient satisfaction. The hypotheses for each of the three dependent variables are formulated based on assumptions and beliefs guided by the literature. Production theory suggests that the existence of a volunteer labor force will increase the input of labor services and in turn improve production. Because labor services is identified as one input in the production function, a higher number of volunteers or volunteer hours should lead to fewer paid positions or paid hours, thus producing a cost savings, and all else equal improving the profit margin. 
The dependent variable of patient satisfaction is related to the quality of health care provided by the organization. According to Donabedian (Flood et. al., 1997), three classes of measures are used to evaluate quality; structural, process, and outcome measures. Structure is defined as the organization's design and governance or management. Structural measures determine the organization's ability to be effective. Examples of structural indicators include accreditation, percentage of board certified physicians, quality of staff education, the numbers of staff, and the use of information systems. Volunteerism could be considered a structural measure. Specifically, volunteerism may be classified as a structural measure of the effectiveness within the human resources management domain. Process indicators are related to the organization's ability to carry out work. Quality assurance activities and organizational climate are all examples of process measures (Flood et. al., 1997).

Outcome measures are used to determine where changes in the structure or process may be necessary. Outcome indicators include patient functional health status, return on assets, operating margins and staff satisfaction (Flood et. al., 1997). The dependent variable of patient satisfaction is an outcome measure within the clinical care domain. The structure, process, and outcome measures can be visualized as a linear model in which the indicators are interrelated (Donabedian, 2003).

In addition to the four objectives identified throughout organizational performance theory, a number of factors are recognized in previous research because of their impact on organizational performance. They include quality of professional staff, high standards, and experience with other cases of the same type, more formally organized professional staffs with well-defined coordination and conflict management processes, participative organization cultures emphasizing team approaches, timely and accurate performance feedback, and active 
management of environmental forces (Flood et. al., 1997). Quality of professional staff, high standards, formal organization of staff, and timely and accurate feedback are each related to the professionalism measure within this study. The recruitment, retention, and assignment to service areas that utilize the applicant's strength all enhance the quality of the volunteer staff.

Furthermore, the use of a director of volunteer services whom is responsible for the coordination of volunteer activities helps the organization to set high standards. The coordination of the volunteer program also enhances the professionalism and formalization of volunteer staff. For instance, written policies and job descriptions or service area guidelines aid in the proficiency and the performance of volunteers. Finally, feedback such as patient satisfaction surveys allow for the assessment of performance standards and improvement in quality areas (Flood et. al., 1997).

Organizational performance theory, production theory, and Donabedian structureprocess-outcome theory each contribute to the framework for this study. Figure 1 below illustrates the relationship between the explanatory, dependent, and control variables. The explanatory variable, volunteerism, and the control variables (bed size, RN hours/FTE hours, system, ownership, and teaching status) will be regressed against each of the dependent variables (profit margin, volunteer cost savings, and patient satisfaction). 


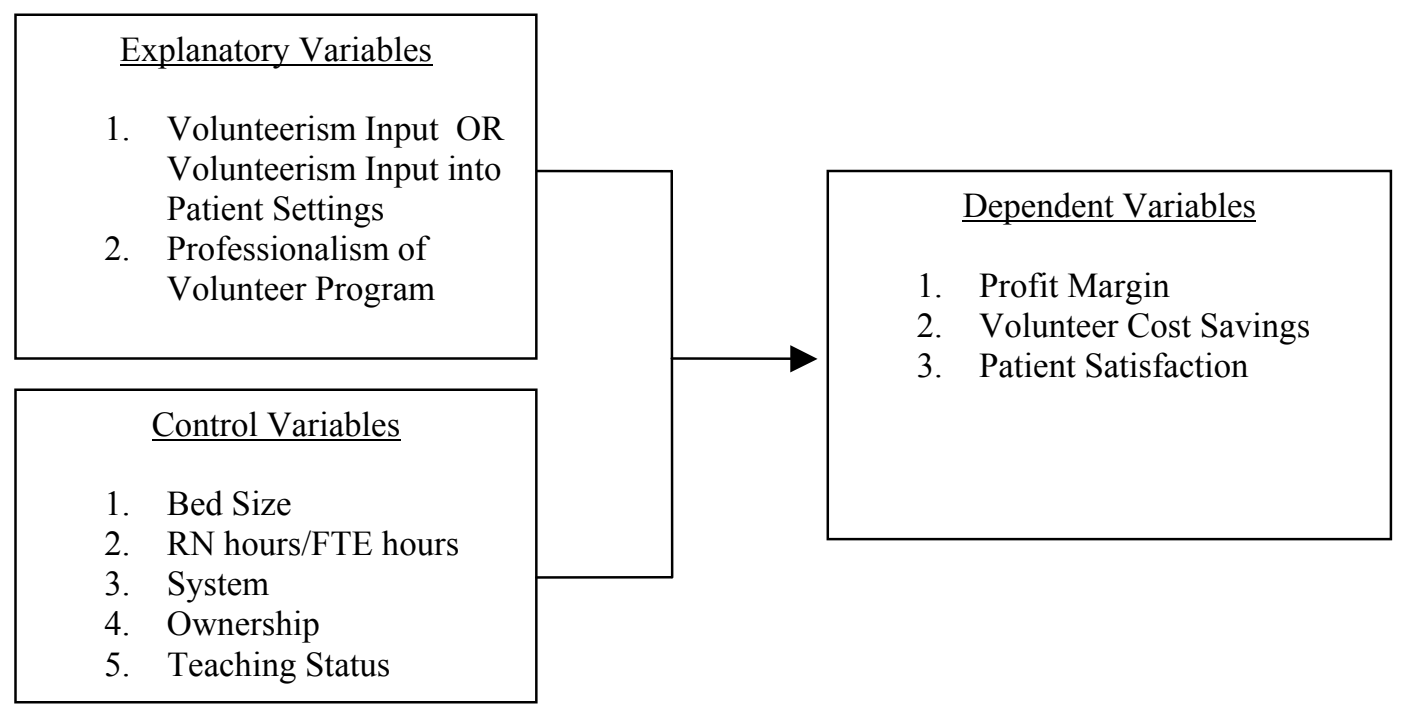

Figure 1 Conceptual Framework of All Variables

$\underline{\text { Research Questions and Hypotheses }}$

The literature and theoretical framework can be used as a guide in the development of research questions. The following research questions and corresponding hypotheses will be examined in the proposed study:

1. Do higher levels of volunteerism within a hospital improve the hospital's profit margin?

H1: There is a relationship between higher levels of volunteerism and hospital profit margin.

$\mathbf{H O}_{1}$ : There is no relationship between higher levels of volunteerism and hospital profit margin.

2. Do higher levels of professionalism of volunteer programs improve the hospital's profit margin?

H2: There is a relationship between higher levels of professionalism of volunteer programs and hospital profit margin. 
$\mathbf{H O}_{2}$ : There is no relationship between higher levels of professionalism of volunteer programs and hospital profit margin.

3. Do higher levels of volunteerism within a hospital save costs?

H3: There is a relationship between higher levels of volunteerism and volunteer cost savings.

$\mathbf{H 0}_{3}$ : There is no relationship between higher levels of volunteerism and volunteer cost savings.

4. Do higher levels of professionalism of volunteer programs within a hospital save costs?

H4: There is a relationship between higher levels of professionalism of volunteer programs and volunteer cost savings.

$\mathbf{H O}_{4}$ : There is no relationship between higher levels of professionalism of volunteer programs and volunteer cost savings.

5. Do higher levels of volunteerism in patient settings within a hospital improve patient satisfaction?

H5: There is a relationship between higher levels of volunteerism in patient settings and patient satisfaction.

H0 $_{5}$ : There is no relationship between higher levels of volunteerism in patient settings and patient satisfaction.

6. Do higher levels of professionalism of volunteer programs within a hospital improve patient satisfaction?

H6: There is a relationship between higher levels of professionalism of volunteer programs within a hospital and patient satisfaction. 
$\mathbf{H 0}_{6}$ : There is no relationship between higher levels of professionalism of volunteer programs within a hospital and patient satisfaction. 


\section{CHAPTER THREE: METHODOLOGY}

\section{$\underline{\text { Research Design }}$}

In order to complete the study a brief survey was used to collect data on the volunteer programs of Florida hospitals. The survey asked for data from the year 2004. Data from the year 2004 was specified so that archival data from other data sources could be used as verification. At the time of this study, the most recent published data sets were for the year 2004. Archival data sets that are used include American Hospital Association annual survey data and the Agency for Healthcare Administration data for the state of Florida. Following the collection of data, multiple linear regression analysis was run using SPSS.

\section{Survey Sample and Distribution}

The sampling unit for the proposed study is the hospital. For the purposes of this study, all hospitals that are a part of the Florida Association of Directors of Volunteer Services (FADVS) were included in the sample. FADVS works to enhance the delivery of healthcare by developing volunteer resources as a professional organization for directors of volunteer services. FADVS has over 65 members from a variety of Florida healthcare organizations of which the majority represent hospitals. The membership list of consisting of 68 hospitals was utilized as a means of contact for the member hospital's volunteer directors, and an official email was sent in December of 2006 from the Florida Association of Directors of Volunteer Services to their members introducing them to the study. 
Most members that are not hospitals are hospice organizations. Of the 68 hospitals listed on the membership list, 63 are unique non-profit hospitals. Eleven of these have between 100 and 199 licensed beds, 12 have between 200 and 299 beds, 4 have between 300 and 399 beds, 6 have between 400 and 499 beds, 12 have over 500 beds, and 18 have an unknown number of beds prior to the survey. The application of the official e-mail was used to increase the typical study response rate of less than 50 percent to a response rate of $54.41 \%$.

In order to make the sample less biased, the survey was purposefully distributed to all hospitals within the state of Florida regardless of their membership in FADVS. This follow-up effort was also able to improve sample size. According to the American Hospital Association data set there were 242 hospitals in the state of Florida in 2004. However, upon examination, 1 of these is considered a hospice and is therefore not relevant to this study. An additional 10 of these are rehab hospitals and are not likely to utilize volunteers. Furthermore, 12 of these have less than 50 beds and due to their small size are unlikely to have a developed volunteer program, but they were still contacted and asked to participate in the study. Therefore, approximately 230 hospitals within the state of Florida are valid to the study. Of the 230 hospitals, 68 are members of FADVS and the remaining 172 are not. Regardless of their size, all members of FADVS were contacted in December of 2006 via email and asked to participate in the study. Additionally, the remaining 172 hospitals within the state were contacted by phone in March of 2007 and asked to participate in the study. During these phone calls the director of volunteer services was told about the study and its purpose. They were also offered an incentive of a gift card for participating in the study by completing the survey. The 12 hospitals with fewer than 50 beds declined to participate in the study because they either did not have a volunteer program or only used volunteers in their gift shops. In all, 64 additional hospitals expressed interest in 
participating in the study when contacted by phone. That same month, these 64 hospitals were sent an email introducing the study with the survey attached. They were also provided with contact information should they need assistance or clarification. Incentives of gift cards were offered for every complete survey that was emailed or faxed back. Throughout April and May of 2007, a minimum of three follow up phone calls were made to encourage the participation of non-respondents. Follow up phone calls were also used during this time to obtain any incomplete survey areas.

Table 1 below illustrates the distribution of the surveys to both FADVS and non-FADVS hospitals. During wave 1 of the sample distribution, surveys were distributed by e-mail to all 68 members of FADVS and 37 complete surveys were received for a FADVS response rate of $54.41 \%$. During wave 2 of the sample distribution, 172 hospitals were contacted and asked to participate in the study. Of the 172, an additional 64 hospitals agreed and were sent surveys. 13 more complete surveys were returned for a wave 2 response rate of $7.5 \%$. After both waves of sample distribution the total universe was 230 hospitals. Of the 132 surveys distributed, 50 were completed and returned, resulting in a total response rate of $21.7 \%$.

Table 1 Survey Distribution

\begin{tabular}{llll} 
& $\begin{array}{l}\text { Wave 1 } \\
\text { (FADVS) }\end{array}$ & $\begin{array}{l}\text { Wave 2 } \\
\text { (Other Florida Hospitals) }\end{array}$ & Total \\
\hline Total \# of Hospitals & 68 & 172 & 230 \\
\# of Hospitals Sent Survey & 68 & 64 & 132 \\
\# of Hospitals Responded & 37 & 13 & 50 \\
Response Rate & $54.41 \%$ & $7.5 \%$ & $21.7 \%$
\end{tabular}


Table 2 below illustrates a comparison between all hospitals within the state of Florida and the 132 hospitals that were sent the survey and made up the study sample. For Table 2 as well as Tables 3 and 4, both t-test and chi-square statistics are shown depending upon whether the comparison variables are continuous (i.e., bed size and RN hours/FTE hours) or noncontinuous (i.e., system, ownership, and FADVS membership). The results of the one sample ttest or non-parametric chi-square test for bed size, RN hours/FTE hours, ownership, and FADVS membership each displayed a $\mathrm{p}$ value below 0.05 , and in some cases a p value below 0.01 , illustrating that for these variables there is a significant difference between the mean for the hospitals within Florida and the study sample. Thus, despite the best of intentions the sample is different on 4 of the 5 criteria used to compare to the population. Therefore, the results must be interpreted with caution and the findings generalizabilty is limited. While 4 of the 5 variables were not comparable the system variable was found to be comparable between hospitals in the state of Florida and hospitals that were sent the survey. These results are further demonstrated by comparing the means between the two sub-samples, as seen in Table 2 . 
Table 2 Descriptive Statistics for Hospitals within Florida Compared to Hospitals that were Sent the Survey

\begin{tabular}{|c|c|c|c|c|c|c|c|c|}
\hline \multirow[b]{2}{*}{ Variable } & \multicolumn{3}{|c|}{$\begin{array}{l}\text { Descriptive Statistics for } \\
\text { Florida Hospitals }\end{array}$} & \multicolumn{3}{|c|}{$\begin{array}{c}\text { Descriptive Statistics for } \\
\text { Hospitals that were sent } \\
\text { the Survey }\end{array}$} & \multirow{2}{*}{$\begin{array}{c}\text { One } \\
\text { Sample } \\
\text { t-test } \\
t\end{array}$} & \multirow{2}{*}{$\begin{array}{c}\text { Non- } \\
\text { parametric } \\
\text { test } \\
\text { Chi- } \\
\text { square }\end{array}$} \\
\hline & $n$ & $\begin{array}{c}\text { Mean } \\
\text { and } \\
\text { Percent }\end{array}$ & $\begin{array}{c}\text { Std. } \\
\text { Deviation }\end{array}$ & $n$ & $\begin{array}{c}\text { Mean } \\
\text { and } \\
\text { Percent }\end{array}$ & $\begin{array}{c}\text { Std. } \\
\text { Deviation }\end{array}$ & & \\
\hline Bed Size & 218 & 248.67 & 247.23 & 132 & 319.93 & 268.46 & $3.051 * *$ & \\
\hline $\begin{array}{l}\text { RN } \\
\text { hours/FTE } \\
\text { hours }\end{array}$ & 218 & 0.2545 & 0.0678 & 132 & 0.2766 & 0.0572 & $4.435 * *$ & \\
\hline $\begin{array}{l}\text { System } \\
\text { Non-system } \\
\text { System }\end{array}$ & 218 & $\begin{array}{c}0.69 \\
31.2 \% \\
68.8 \%\end{array}$ & 0.464 & 132 & $\begin{array}{l}0.74 \\
25 \% \\
75 \%\end{array}$ & 0.432 & & 2.364 \\
\hline 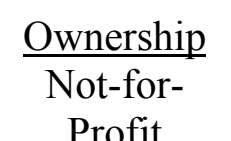 & 218 & $\begin{array}{l}0.7110 \\
39.5 \%\end{array}$ & 0.6534 & 132 & $\begin{array}{c}0.58 \\
50.8 \%\end{array}$ & 0.670 & & $6.859 *$ \\
\hline $\begin{array}{c}\text { For-Profit } \\
\text { Government }\end{array}$ & & $\begin{array}{l}48.6 \% \\
10.9 \%\end{array}$ & & & $\begin{array}{l}38.6 \% \\
10.6 \%\end{array}$ & & & \\
\hline $\begin{array}{l}\frac{\text { FADVS }}{\text { Non- }} \\
\text { member } \\
\text { Member }\end{array}$ & 218 & $\begin{array}{c}0.31 \\
68.8 \% \\
31.2 \%\end{array}$ & 0.464 & 132 & $\begin{array}{c}0.52 \\
48.5 \% \\
51.5 \%\end{array}$ & 0.502 & & $25.401 * *$ \\
\hline
\end{tabular}

$* \mathrm{p} \leq 0.05$

$* * \mathrm{p} \leq 0.01$

Table 3 below illustrates a comparison between the 132 hospitals that were sent the survey and the survey respondents. The results of the non-parametric chi-square test for ownership and FADVS membership each displayed a p value below 0.01 illustrating that for these variables there is a significant difference between the mean for the 132 hospitals that were sent the survey and the survey respondents. On the other hand, the results of the one sample t-test for bed 
size, RN hours/ FTE hours, and the results of the non-parametric chi-square test for system did not find a $\mathrm{p}$ value that was less than 0.05 and therefore these three variables are comparable between the study sample and the survey respondents. The results show that on $3 / 5$ or $60 \%$ of the measures, the sample matches the sampling frame and in the other $40 \%$ it does not. Thus, the results must be cautiously interpreted and the generalizability of the findings may be limited possibly to only those that agreed to participate. These results are further demonstrated by comparing the means between the two sub-samples, as seen in Table 3. 
Table 3 Descriptive Statistics for Hospitals that were sent the survey Compared to Survey Respondents

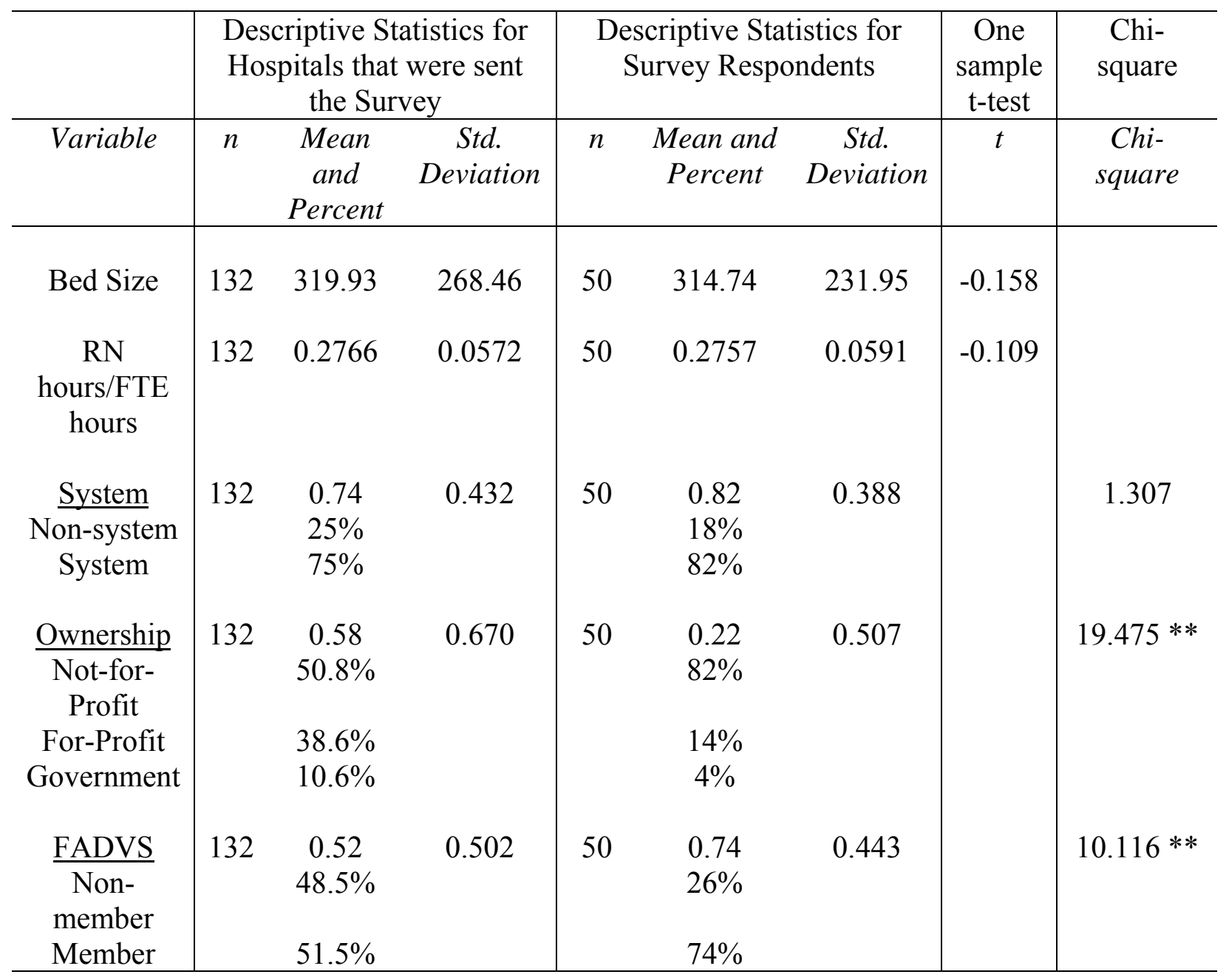

$* \mathrm{p} \leq 0.05$

$* * \mathrm{p} \leq 0.01$

Table 4 below summarizes the results of a comparison between all hospitals in Florida and the survey respondents. Based on Table 4, the bed size, RN hours/FTE hours, system, ownership, and FADVS variables are dissimilar between state hospitals and the study participants. In regards to system membership, the majority of the participants are part of a larger organizational system, but this is also true of most hospitals within the state of Florida; however, the chi-square test showed a statistically significant difference. Ownership in the study 
is overrepresented with a greater proportion of not-for-profit hospitals. Based on AHA data $39 \%$ of hospitals within the state are not-for-profit while $46.3 \%$ are for profit facilities. In contrast, $82 \%$ of study participants were not-for-profit hospitals. FADVS membership is also overrepresented in the study. While there was nearly a 50/50 split in distribution to the 132 hospitals in the study sample in regards to FADVS membership, a larger percentage of respondents were members of FADVS. Because of the differences in bed size, RN hours/FTE hours, system, ownership and FADVS membership between the state and the study sample the sample is overall dissimilar from Florida as a whole. The results show that for all of the measures the sample fails to match the sampling frame. Thus, the results must be cautiously interpreted and the generalizability of the findings may be limited possibly to only those that agreed to participate and are not generalizable to all hospitals in the state. In summary, the study hospitals were slightly larger in size, were more representative of non-profit, were system affiliated, and were FADVS member hospitals. 
Table 4 Descriptive Statistics for Hospitals within Florida Compared to Survey Respondents

\begin{tabular}{|c|c|c|c|c|c|c|c|c|}
\hline \multirow[b]{2}{*}{ Variable } & \multicolumn{3}{|c|}{$\begin{array}{l}\text { Descriptive Statistics for } \\
\text { Florida Hospitals }\end{array}$} & \multicolumn{3}{|c|}{$\begin{array}{l}\text { Descriptive Statistics for } \\
\text { Survey Respondents }\end{array}$} & \multirow{2}{*}{$\begin{array}{c}\text { One } \\
\text { Sample } \\
\text { t-test }\end{array}$} & \multirow{2}{*}{$\begin{array}{c}\text { Chi- } \\
\text { square }\end{array}$} \\
\hline & $n$ & $\begin{array}{c}\text { Mean } \\
\text { and } \\
\text { Percent }\end{array}$ & $\begin{array}{c}\text { Std. } \\
\text { Deviation }\end{array}$ & $n$ & $\begin{array}{c}\text { Mean } \\
\text { and } \\
\text { Percent }\end{array}$ & $\begin{array}{c}\text { Std. } \\
\text { Deviation }\end{array}$ & & \\
\hline Bed Size & 218 & 248.67 & 247.23 & 50 & 314.74 & 231.95 & $2.014 *$ & \\
\hline $\begin{array}{c}\text { RN } \\
\text { hours/FTE } \\
\text { hours }\end{array}$ & 218 & 0.2545 & 0.0678 & 50 & 0.2757 & 0.0591 & $2.536 *$ & \\
\hline $\begin{array}{l}\text { System } \\
\text { Non-system } \\
\text { System }\end{array}$ & 218 & $\begin{array}{c}0.69 \\
31.2 \% \\
68.8 \%\end{array}$ & 0.464 & 50 & $\begin{array}{l}0.82 \\
18 \% \\
82 \%\end{array}$ & 0.388 & & $4.059 *$ \\
\hline $\begin{array}{c}\text { Ownership } \\
\begin{array}{c}\text { Not-for- } \\
\text { Profit }\end{array}\end{array}$ & 218 & $\begin{array}{l}0.7110 \\
39.5 \%\end{array}$ & 0.6534 & 50 & $\begin{array}{l}0.22 \\
82 \%\end{array}$ & 0.507 & & $36.986 * *$ \\
\hline $\begin{array}{l}\text { For-Profit } \\
\text { Government }\end{array}$ & & $\begin{array}{l}48.6 \% \\
10.9 \%\end{array}$ & & & $\begin{array}{l}14 \% \\
4 \%\end{array}$ & & & \\
\hline $\begin{array}{c}\frac{\text { FADVS }}{\text { Non-member }} \\
\text { Member }\end{array}$ & 218 & $\begin{array}{c}0.31 \\
68.81 \% \\
31.19 \% \\
\end{array}$ & 0.464 & 50 & $\begin{array}{l}0.74 \\
26 \% \\
74 \%\end{array}$ & 0.443 & & $42.697 * *$ \\
\hline
\end{tabular}

As shown in Tables 2, 3, and 4 of the previous chapter, the study sample is not representative of the universe of hospitals within the state of Florida. Despite the differences illustrated in Tables 2,3, and 4 the data obtained can still be used as it can be generalized to hospitals that participated in the study. In addition, the results can be generalized to those hospitals that are comparable in several characteristics such as Florida's hospitals that are slightly larger in size, system affiliated, and not-for-profit and FADVS member hospitals. 
$\underline{\text { Archival Data Sources and Sample }}$

Archival data from the American Hospital Association Annual Survey for 2004 was used as the initial resource for information on the control variables and performance variables. Additionally financial data from the Agency for Health Care Administration for 2004 was used to determine the profit margin and hospital budgets. This data was matched to the data collected from FADVS member hospitals identified by name in the survey. The control variables that initially used data from these sources include bed size, RN hours/ FTE hours, not-for-profit or for-profit categorization, and whether the hospital is part of a larger system.

Performance variables include profit margin and human resources costs. Other performance data include patient satisfaction scores of the overall rating of care from the Press Ganey Associates Survey, Gallup, or NCR Picker which is provided by the hospitals themselves and presented as a question in the survey instrument. While these surveys use different measures the results were all reported as a percentile with one-hundred percent being the highest level of patient satisfaction and lower percentages representing lower scores. The Press Ganey Survey of Martin Memorial Hospital can be found in the Appendix.

Not only did the hospitals within the sample provide archival data on patient satisfaction, they also provided data on the explanatory variable, volunteerism. For this purpose, a survey was internally distributed to the volunteer directors of the association's member hospitals. This survey was distributed by e-mail through the official Florida Association of Director of Volunteer Services email list. Any necessary follow-up also took place via e-mail and telephone. In addition to this survey, administrators were asked to provide any archival data that 
they may have had on their volunteer programs. Participants responded to the survey questions using data for the year 2004.

$\underline{\text { Instrumentation and Measures }}$

A brief survey created for this study and reviewed by the FADVS executive board was used to collect data on hospital information, volunteerism, and performance measures within the sample. Based on the responses of the survey, a volunteerism ratio was calculated for each hospital. This ratio allows for comparisons to be made within the sample. Moreover, a volunteerism index based on survey responses was created using scores of individual organization's degree of volunteerism. For the purposes of the patient satisfaction variable the volunteerism measure utilized a ratio of total volunteer hours in volunteer service assignments that could influence the patients over total volunteer hours. These areas of direct patient contact include acute care nursing, nursery/NICU, maternity, AIDS unit, critical care nursing, emergency department, outpatient clinic, pharmacy, support groups, admitting, baby photos, blood donor program, cafeteria/kitchen, clerical assistance, discharge, gift shop, information desk, messenger/escort service, mobile vans, offsite programs, parking, pet therapy, telephone friend, transporters, and waiting room host. Questions included in the survey instrument can be found in the Appendix.

The operational definitions for all the variables used in the study can be found in Table 5 . The dependent variables include profit margin, volunteer cost savings, and patient satisfaction.

To develop a measurement of the degree of volunteerism in a hospital, the number of volunteer hours was divided by the number of total employee FTE hours to create a ratio 
measurement. This measurement allows for a degree of volunteerism to be determined. After collecting data on FTEs they were converted to FTE hours using the rate of 40 hours per week or 173.3 hours per month (Volgistics, 2006). The explanatory variable, volunteerism, was able to be calculated using the volunteer hours and the conversion of FTEs to employee hours. The use of volunteer hours rather than number of volunteers was selected as the volunteerism measure because it accounts for the variation in hours volunteered. For the patient satisfaction regression the volunteerism ratio of volunteer hours in areas where patient contact could occur over total employee FTE hours was used as the explanatory variable.

In addition to these measures, a professionalism of the volunteer program index was created using the survey results. This index serves as an explanatory variable, using an assigned rank based on the number of responses that apply to the organization in each category of written volunteer policies, written volunteer service guidelines, volunteer interview and screening process, volunteer recruitment method, volunteer labor risk management plan, and volunteer orientation. There are twelve types of policies listed in the survey; hence an organization that has all twelve will have a high ranking of formalization of written volunteer policies. Similarly, there are eight specific categories of volunteer service guidelines listed in the survey so that an organization with eight or more of these would be highly formalized in this area. Five processes of volunteer interview and screening are listed on the survey allowing for a maximum score of five. Also, there are four recruitment methods suggesting that an organization utilizing all four of these is more professional than those using none. There are three types of volunteer labor risk management plans and three possibilities of volunteer orientation. Again, organizations with more of these were considered more formalized. In total there are thirty-four possible areas that fall into the professionalism of the volunteer program, allowing for a score ranging from zero to 
thirty-four to be assigned to each hospital. Hospitals with the highest scores were ranked as the most formally professional.

Control variables are bed size, RN hours/FTE hours, system, ownership, and teaching status. Operational definitions are in Table 5. 
Table 5 Operational Definitions of All Variables in This Study

\begin{tabular}{|c|c|c|c|c|c|}
\hline Variable & Description & Type & Code & Units & Source \\
\hline \multicolumn{6}{|c|}{ Dependent Variables } \\
\hline Profit Margin & $\begin{array}{c}\text { Hospital's annual operating } \\
\text { margin (operating revenues - } \\
\text { operating } \\
\text { expenses)/operating revenues }\end{array}$ & $\begin{array}{l}\text { Dependent; } \\
\text { Interval }\end{array}$ & All values & US Dollars & $\begin{array}{c}\text { Survey } \\
\text { instrument } 8 ; \\
\text { verified by } \\
\text { AHCA data }\end{array}$ \\
\hline $\begin{array}{l}\text { Volunteer Cost } \\
\text { Savings }\end{array}$ & $\begin{array}{c}\text { Cost of volunteers if replaced } \\
\text { by paid employees minus } \\
\text { associated cost of volunteer } \\
\text { program over total budget }\end{array}$ & $\begin{array}{l}\text { Dependent; } \\
\text { Interval }\end{array}$ & All values & $\begin{array}{c}\text { Volunteer hours } \\
\text { x hourly paid } \\
\text { rate in US } \\
\text { Dollars - } \\
\text { operating budget } \\
\text { and salaries } \\
\end{array}$ & $\begin{array}{c}\text { Survey } \\
\text { instrument }[13- \\
(17+18)] / 10, \\
\text { total budget } \\
\text { verified by } \\
\text { AHCA data }\end{array}$ \\
\hline $\begin{array}{l}\text { Patient } \\
\text { satisfaction }\end{array}$ & $\begin{array}{c}\text { Patient overall rating of care } \\
\text { from Press Ganey, Gallup, } \\
\text { NCR Picker or other internal } \\
\text { surveys }\end{array}$ & $\begin{array}{l}\text { Dependent; } \\
\text { Percentage }\end{array}$ & $1-100$ & Percentage & $\begin{array}{c}\text { Survey } \\
\text { instrument 9; } \\
\text { internal patient } \\
\text { satisfaction } \\
\text { surveys }\end{array}$ \\
\hline \multicolumn{6}{|c|}{ Explanatory Variables } \\
\hline $\begin{array}{l}\text { Volunteerism } \\
\text { Input }\end{array}$ & \begin{tabular}{|c|} 
Number of volunteer \\
hours/total hospital employee \\
FTE hours
\end{tabular} & \begin{tabular}{|c|} 
Explanatory; \\
Ratio (for profit \\
margin and \\
volunteer cost \\
savings) \\
\end{tabular} & All values & $\begin{array}{l}\text { Number of } \\
\text { volunteer } \\
\text { hours/size }\end{array}$ & $\begin{array}{c}\text { Survey } \\
\text { instrument } 15 / 6\end{array}$ \\
\hline \begin{tabular}{|l|} 
Volunteerism \\
Input in Patient \\
Settings
\end{tabular} & $\begin{array}{c}\text { Volunteer hours in volunteer } \\
\text { service assignments with } \\
\text { patient contact/total hospital } \\
\text { employee FTE hours }\end{array}$ & $\begin{array}{l}\text { Explanatory; } \\
\text { Ratio } \\
\text { (for patient } \\
\text { satisfaction) }\end{array}$ & All values & $\begin{array}{l}\text { Number of } \\
\text { volunteer hours } \\
\text { in patient } \\
\text { settings/size }\end{array}$ & $\begin{array}{c}\text { Survey } \\
\text { instrument } 16 / 6\end{array}$ \\
\hline $\begin{array}{l}\text { Professionalism } \\
\text { of Volunteer } \\
\text { Program }\end{array}$ & $\begin{array}{l}\text { Formalization of volunteer } \\
\text { recruitment, interview, risk } \\
\text { management, etc. }\end{array}$ & $\begin{array}{l}\text { Explanatory; } \\
\text { Ordinal }\end{array}$ & $\mid \begin{array}{c}\text { Scale } 0- \\
34,34 \text { being } \\
\text { highest }\end{array}$ & NA & $\begin{array}{c}\text { Survey } \\
\text { instrument } 11 \\
12,19,20,21 \\
22\end{array}$ \\
\hline \multicolumn{6}{|c|}{ Control Variables } \\
\hline Bed Size & Number of hospital beds & Control; Interval & All values & Number of beds & $\begin{array}{l}\text { Survey } \\
\text { instrument } 2 \text {; } \\
\text { verified by } \\
\text { AHA data }\end{array}$ \\
\hline $\begin{array}{l}\text { RN hours/FTE } \\
\text { hours }\end{array}$ & $\begin{array}{c}\text { Number of RN hours/total } \\
\text { hospital employee FTE hours }\end{array}$ & Control; Ratio & All values & $\begin{array}{l}\text { Number of RN } \\
\text { hours/size }\end{array}$ & $\begin{array}{l}\text { Survey } \\
\text { instrument } 6 \\
\text { verified by } \\
\text { AHA data }\end{array}$ \\
\hline System & $\begin{array}{l}\text { Hospital ownership by a } \\
\text { larger system }\end{array}$ & Control; Binary & $\begin{aligned} \text { Yes } & =1, \text { No } \\
& =0\end{aligned}$ & NA & $\begin{array}{c}\text { Survey } \\
\text { instrument } 7\end{array}$ \\
\hline Ownership & $\begin{array}{l}\text { Hospital categorization as } \\
\text { not-for-profit (NP) or for- } \\
\text { profit (FP) }\end{array}$ & Control; Binary & $\begin{array}{c}\mathrm{NP}=0, \mathrm{FP} \\
\quad=1 \\
\text { public/gov't } \\
\quad=2\end{array}$ & NA & $\begin{array}{c}\text { Survey } \\
\text { instrument 5; } \\
\text { verified by } \\
\text { AHA data }\end{array}$ \\
\hline Teaching Status & $\begin{array}{l}\text { Hospital categorization as a } \\
\text { teaching hospital }\end{array}$ & Control; Binary & $\begin{aligned} \text { Yes } & =1, \text { No } \\
& =0\end{aligned}$ & NA & $\begin{array}{c}\text { Survey } \\
\text { instrument } 4\end{array}$ \\
\hline
\end{tabular}


$\underline{\text { Other Variables Considered }}$

Originally, a fourth dependent variable of patient safety was going to be included in this study. Based on the literature and the theoretical framework this measure of organizational performance is likely to be influenced by the level of volunteerism within a hospital. The number of adverse events was going to be used as a measure of patient safety. Unfortunately, after issuing the survey to the FADVS board it became clear that this data was unobtainable. Many directors of volunteer services felt that it was sensitive information that they were not cleared to release. While AHCA collects information on adverse events it is only available to researchers at the state level. In order to use this data in this study it would need to be disaggregated to the hospital level. Because of the concerns expressed over the obtainment of this data, the dependent variable of patient safety was dropped from the study.

\section{$\underline{\text { Statistical Methods }}$}

After reviewing the data it became evident that most of the questionnaires were either very complete or very incomplete. Incomplete questionnaires were not included in the data set. Some surveys that were only missing one or two data items were able to be completed using the data from AHA or AHCA and were then included in the data set. In some infrequent cases (5), mean replacement was used for missing data values of those surveys that were missing one or two items that could not be completed using AHA or AHCA data. These methods resulted in a data set of 50 respondents.

The statistical software application SPSS was used to evaluate data. Descriptive statistics including mean, median, and standard deviation were used to examine the distribution of the 
variables. Partial regression coefficients were determined for each of the variables in the regression equation. Then, statistical significance was calculated for each partial regression coefficient. For the purpose of these tests, a $\mathrm{P}$ value of $<0.05$ is considered statistically significant (Gliner \& Morgan, 2000). $\mathrm{R}^{2}$ was used to evaluate the goodness of fit of the models in this study.

Multiple linear regression analysis was used to address the research question. In doing so, the analysis explored the relationship between the explanatory variables related to volunteerism and the dependent variables related to hospital performance. This method helped to determine whether there is an association and the degree of association among variables. The following set of equations, with $\mathrm{u}$ as the unexplained residual variation in the dependent variable, is representative of the study and its variables:

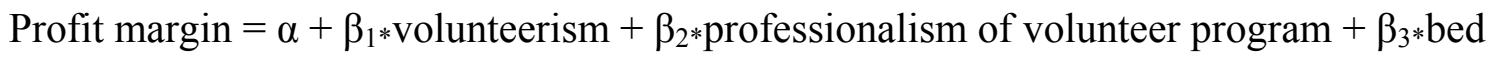

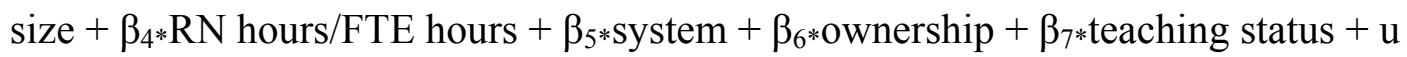

Volunteer cost savings $=\alpha+\beta_{1} *$ volunteerism $+\beta_{2} *$ professionalism of volunteer program

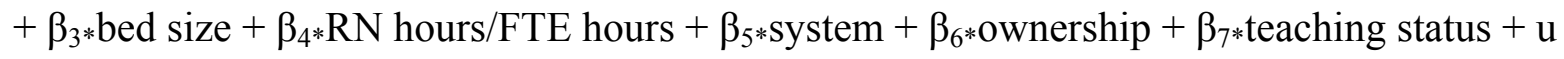

Patient satisfaction $=\alpha+\beta_{1 * \text { volunteerism in patient settings }+\beta_{2} * \text { professionalism of }}$

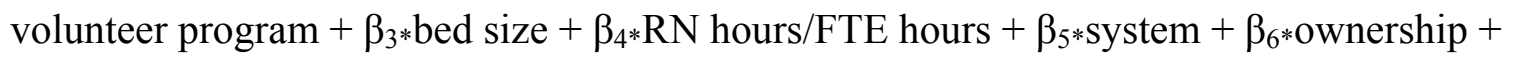
$\beta_{7 * \text { teaching status }+\mathrm{u}}$

Because three different dependent variables are being measured, three different regression equations were used.

Furthermore, outliers influencing the fit of the line were identified and removed from each regression. Using a box plot of Cook's Distance extreme cases and other outliers were identified. The box plots for each of the regression equations can be found in the Appendices D, 
$\mathrm{E}$, and $\mathrm{F}$. The cases marked with an asterisk are extreme outliers and were removed from the regression equations. Other outliers include any cases above the black line which were also removed from the regression equations.

\section{$\underline{\text { Priori Power Analysis }}$}

A priori power analysis was completed before the data was obtained using simulation in order to compute sample sizes for the survey. This was done before the investigation to ensure that an adequate sample size for multivariate analysis can be performed.

Using the statistical software Advisor Inquiry the expected power of the proposed study was determined. With a sample size of at least 39 , a significance level of $0.05,9$ variables including the dependent variable, and the estimated amount of the dependent variable that can be explained by the control and explanatory variables $\left(\mathrm{R}^{2}\right)$ of 0.5 , the power of the analysis is $97 \%$. Other possible $\mathrm{R}^{2}$ values were plugged into the program and even at a low $\mathrm{R}^{2}$ value of 0.3 the power of the analysis was $74 \%$. Because the response rate did not result in a sample size of less than 39 the power analysis is applicable and it is unlikely that the power will be below $80 \%$. This illustrates that there is little concern over the power of the study.

Furthermore, originally 9 variables were going to be used in the analysis but one of the control variables was removed (FTE) because it was being used in the volunteerism measures to control for size. Therefore, a total of 8 variables are included in each of the regression equations. The use of one less variable will improve the results of the power analysis. 


\section{CHAPTER FOUR: FINDINGS}

\section{$\underline{\text { Descriptive Statistics }}$}

Table 6 lists the descriptive statistics for all variables in this study. For each variable there is an $\mathrm{N}$ of 50 because verification of data from archival sources and the application of mean replacement for five missing values resulted in 50 complete surveys. The dependent variables illustrated in Table 6 include patient satisfaction, volunteer cost savings, and profit margin. The minimum patient satisfaction score within the sample is .58 or $58 \%$ and the maximum is .99 or 99\%, again demonstrating the variation among study participants. The mean patient satisfaction score is .8154 or $81.54 \%$ while the median is .8215 or $82.15 \%$. Volunteer cost savings as a percentage of total hospital expenses range from .00 or $0 \%$ to .71 or $71 \%$ with a mean of .0309 or $3.09 \%$ and a median of 0.0068 or $0.68 \%$. Profit margins vary from -0.11 or a loss of $11 \%$ to .16 or $16 \%$, average and median of 0.0413 or $4.13 \%$.

The explanatory variables in Table 6 include volunteer hours divided by FTE hours, volunteerism in patient settings, which is measured as volunteer hours in patient settings divided by FTE hours, and professionalism which is an index ranging from possible scores of 0-34 with 34 being the most professional. Volunteerism input ranges from .00 to .10 illustrating that there is between 0 minutes of volunteer time for every FTE hour to 6 minutes of volunteer time for every FTE hour. The mean of this volunteerism variable is 0.0265 and the median is 0.0211 . Volunteerism in patient settings values range from 0 to 0.07 illustrating that in all of the facilities at least half of volunteer hours are in patient settings. The mean for this variable is 0.0197 and the median is 0.0153 . The variable of professionalism categorizes each study participant into an index of formalization of their volunteer program. The minimum possible value is 1 with the 
maximum being 34. Within the index those facilities with a value of 34 are the most professional. These scores were used as the professionalism variable. The frequencies of the various professionalism scores can be found in the Appendix. As shown in Table 6, the professionalism variable ranges from 9 to 34 with a mean score of 21.58 and a median score of 21. This shows that every participating facility has some level of professionalism to their volunteer program.

Finally, the control variables include bed size, RN hours/FTE hours, system, ownership, and teaching status. The minimum bed size for this sample of 50 is 27 while the maximum is 935 beds with a mean of 314.74 beds and a median of 249.5. This demonstrates a great deal of variation in size within the sample. The variation in RN hours/FTE hours is also evident with a minimum of 0.18 , a maximum of 0.5 , a mean of 0.2757 and a median of 0.2776 . Because the system variable was coded as 0 or 1 the mean of 0.82 and median of 1 , for this variable tells us that a greater number of study participants have a value of 1 , meaning that they are part of a system. In fact, $82 \%$ of the participants are members of a system while $18 \%$ are not. The same logic can be applied to the variables of teaching status and ownership. The teaching status mean of 0.28 and median of 0 tells us that a greater number of study participants have a value of 0 and hence are not teaching facilities. Seventy-two percent of study participants were not teaching facilities while $28 \%$ were categorized as teaching facilities. Again, the ownership mean of 0.22 and median of 0 tells us that greater deals of study participants are not-for-profit facilities. Based on frequencies, $82 \%$ of study participants are not-for-profit, while $14 \%$ are for profit and $4 \%$ are government facilities.

While the descriptive statistics are shown for all 50 responding facilities, there was evidence of skewness in the distribution. Therefore, outliers were removed in each of the 
regression models. Cook's distance was used to identify outliers for each individual regression equation. For the profit margin regression, the $\mathrm{N}$ is 42 after removing outliers. Likewise, for the volunteer cost savings regression, the $\mathrm{N}$ is 42 after cleaning the data to remove outliers. Also, for the final regression related to patient satisfaction, the $\mathrm{N}$ is 44 after the removal of outliers. In the case of the profit margin and volunteer cost savings regressions 8 out of 50 of the cases have been removed due to them being outliers. Because this is a net reduction of $16 \%$ of the total sample there is likely to be an affect on the analysis. Removing the outliers is likely to improve the power of the analysis and decrease error variance, but their removal may also bias or influence the results of the analysis. This is also true to a lesser degree of the patient satisfaction regression in which 6 out of 50 cases have been removed because they were identified as outliers. These outliers were likely to be so far outside of the norm that they were in no way representative of the sample. The identification and removal of these outliers is further discussed in relation to each hypothesis below. 
Table 6 Descriptive Statistics for All Variables in this Study

\begin{tabular}{l|cccccc}
\hline & $N$ & Minimum & Maximum & Mean & Median & $\begin{array}{c}\text { Std. } \\
\text { Deviation }\end{array}$ \\
\hline & & & & & & \\
Dependent Variables & & & & & & \\
Profit Margin & 50 & -0.11 & 0.16 & 0.0413 & 0.0413 & 0.04157 \\
$\begin{array}{l}\text { Volunteer Cost } \\
\text { Savings }\end{array}$ & 50 & 0.00 & 0.71 & 0.0309 & 0.0068 & 0.11051 \\
$\begin{array}{l}\text { Patient Satisfaction } \\
\text { Explanatory Variables }\end{array}$ & 50 & 0.58 & 0.99 & 0.8154 & 0.8215 & 0.10971 \\
Volunteerism Input & 50 & 0.00 & 0.10 & 0.0265 & 0.0211 & 0.02120 \\
Volunteerism Input in & 50 & 0.00 & 0.07 & 0.0197 & 0.0153 & 0.01508 \\
Patient Settings & & & & & & \\
Professionalism & 50 & 9 & 34 & 21.58 & 21 & 5.54790 \\
& & & & & & \\
Control Variables & & & & & & \\
Bed Size & 50 & 27 & 935 & 314.74 & 249.5 & 231.95001 \\
RN hours/FTE hours & 50 & 0.18 & 0.50 & 0.2757 & 0.2776 & 0.05908 \\
System & 50 & 0 & 1 & 0.82 & 1 & 0.38881 \\
$\begin{array}{l}\text { Ownership } \\
\text { Teaching }\end{array}$ & 50 & 0 & 2 & 0.22 & 0 & 0.50669 \\
& 50 & 0 & 1 & 0.28 & 0 & 0.45356
\end{tabular}


Table 7 below illustrates a correlation matrix for all variables in this study. There is a very high correlation between the volunteerism input and volunteerism input in patient settings measures $(0.976)$ but these were never both used in the same regression. The matrix illustrates that none of the other variables are over a 0.358 correlation and none exceed the threshold of 0.4 . The highest correlations are found between volunteer cost savings and volunteerism input (0.235), patient satisfaction and professionalism (0.195), patient satisfaction and system (-0.267), patient satisfaction and teaching (0.358), volunteerism input and professionalism (0.215), volunteerism input and bed size (-0.224), volunteerism input and teaching $(-0.319)$, volunteerism in patient settings and professionalism (0.276), volunteerism in patient settings and bed size (0.237), volunteerism in patient settings and RN hours/FTE hours (-0.201), volunteerism in patient settings and teaching $(-0.325)$, professionalism and bed size $(-0.201)$, professionalism and teaching (-0.212), and bed size and teaching (0.220). Most noteworthy of these is the correlations between the dependent and explanatory variables including volunteer cost savings and volunteerism input and patient satisfaction and professionalism. Also noteworthy is the high correlation between the teaching variable and several other variables including patient satisfaction, volunteerism input, volunteerism in patient settings, professionalism, and bed size. 
Table 7 Correlation Matrix for All Variables in this Study

\begin{tabular}{|c|c|c|c|c|c|c|c|c|c|c|c|}
\hline Variable & $\begin{array}{l}\text { Profit } \\
\text { Margin }\end{array}$ & $\begin{array}{l}\text { Volunteer } \\
\text { Cost } \\
\text { Savings }\end{array}$ & $\begin{array}{l}\text { Patient } \\
\text { Satisfaction }\end{array}$ & $\begin{array}{l}\text { Volunteerism } \\
\text { Input }\end{array}$ & $\begin{array}{l}\text { Volunteerism } \\
\text { Input in } \\
\text { Patient } \\
\text { Settings }\end{array}$ & Professionalism & Bed Size & $\begin{array}{l}\text { RN } \\
\text { hours/ } \\
\text { FTE } \\
\text { hours }\end{array}$ & System & Ownership & Teaching \\
\hline $\begin{array}{l}\text { Dependent } \\
\text { Variables }\end{array}$ & & & & & & & & & & & \\
\hline$\overline{\text { Profit Margin }}$ & 1 & 0.090 & -0.278 & -0.115 & -0.140 & -0.054 & 0.040 & 0.010 & 0.054 & 0.073 & -0.140 \\
\hline $\begin{array}{l}\text { Volunteer Cost } \\
\text { Savings }\end{array}$ & 0.090 & 1 & 0.067 & 0.235 & 0.282 & 0.063 & 0.071 & $\begin{array}{l}- \\
0.061\end{array}$ & 0.107 & -0.085 & -0.104 \\
\hline $\begin{array}{l}\text { Patient } \\
\text { Satisfaction }\end{array}$ & -0.278 & 0.067 & 1 & 0.114 & 0.132 & 0.195 & 0.171 & - & -0.267 & 0.104 & 0.358 \\
\hline$\frac{\text { Explanatory }}{\underline{\text { Variables }}}$ & & & & & & & & & & & \\
\hline $\begin{array}{l}\text { Volunteerism } \\
\text { Input }\end{array}$ & -0.115 & 0.235 & 0.114 & 1 & 0.976 & 0.215 & -0.224 & $-\overline{0.148}$ & 0.096 & -0.161 & -0.319 \\
\hline $\begin{array}{l}\text { Volunteerism } \\
\text { Input in Patient } \\
\text { Settings }\end{array}$ & -0.140 & 0.282 & 0.132 & 0.976 & 1 & 0.276 & -0.237 & $-\overline{0.201}$ & 0.111 & -0.143 & -0.325 \\
\hline Professionalism & -0.054 & 0.063 & 0.195 & 0.215 & 0.276 & 1 & -0.201 & - & 0.031 & -0.017 & -0.212 \\
\hline $\begin{array}{l}\text { Control } \\
\text { Variables } \\
\end{array}$ & & & & & & & & & & & \\
\hline Bed Size & 0.040 & 0.071 & 0.171 & -0.224 & -0.237 & -0.201 & 1 & $-\overline{0}$ & 0.062 & 0.118 & 0.220 \\
\hline $\begin{array}{l}\text { RN hours/FTE } \\
\text { hours }\end{array}$ & 0.010 & -0.061 & -0.029 & -0.148 & -0.201 & -0.165 & -0.072 & 1 & -0.077 & 0.061 & 0.140 \\
\hline System & 0.054 & 0.107 & -0.267 & 0.096 & 0.111 & 0.031 & 0.062 & $-\overline{0.077}$ & 1 & -0.106 & 0.060 \\
\hline $\begin{array}{l}\text { Ownership } \\
\text { Teaching }\end{array}$ & $\begin{array}{l}0.073 \\
-0.140\end{array}$ & $\begin{array}{l}-0.085 \\
-0.104\end{array}$ & $\begin{array}{l}0.104 \\
0.358\end{array}$ & $\begin{array}{l}-0.161 \\
-0.319\end{array}$ & $\begin{array}{l}-0.143 \\
-0.325\end{array}$ & $\begin{array}{l}-0.017 \\
-0.212\end{array}$ & $\begin{array}{l}0.118 \\
0.220\end{array}$ & $\begin{array}{l}0.061 \\
0.140\end{array}$ & $\begin{array}{l}-0.106 \\
0.060\end{array}$ & $\begin{array}{l}1 \\
0.820\end{array}$ & $\begin{array}{l}0.082 \\
1\end{array}$ \\
\hline
\end{tabular}




\section{$\underline{\text { Regression Results }}$}

As shown in Tables 2, 3, and 4 of the previous chapter, the study sample is not representative of the universe of hospitals within the state of Florida. Because the results of the one sample t-test and non-parametric chi-square test are statistically significant for all five variables used in the comparison, the following regression results are not generalizable to all hospitals within the state of Florida. However, it can be said that the results are generalizable to those hospitals that responded to the survey. Also, due to the overwhelming proportion of respondents that are members of the Florida Association of Directors of Volunteer Services and hence are more likely to have a more significant emphasis on and concern with volunteer activity the following results can likely be generalized to hospitals with a similar focus on volunteerism. In addition, the results can be generalized to those hospitals that are comparable in several characteristics such as Florida's hospitals that are slightly larger in size, system affiliated, and not-for-profit.

\section{Profit Margin}

The regression results are used to report on each of the six hypotheses. In order to test the hypotheses, linear regression equations were used. For each hypothesis there is an associated regression equation. The first research question asks, "do higher levels of volunteerism within a hospital improve the hospital's profit margin?" Hypothesis 1 is that there is a relationship between higher levels of volunteerism and hospital profit margin. The second research question 
is related to this same equation. It asks, "do higher levels of professionalism of the volunteer program within a hospital improve the hospital's profit margin?" Hypothesis 2 is that there is a relationship between higher levels of professionalism of a volunteer program and profit margin. Volunteerism is defined as volunteer hours/FTE hours in this equation.

After the removal of outliers, the $\mathrm{N}$ for this equation is 42 . Histograms and P-P plots testing the normality of this regression equation can be found in the Appendix.

Table 8 below illustrates the coefficients of the regression equation for the dependent variable profit margin after removing outliers. All variables have p-values that exceed the alpha value of 0.05 , thus none are statistically significant. Neither of the explanatory variables in the equation is statistically significant. Furthermore, none of the control variables in the model including bed size, RN hours/FTE hours, system, ownership, and teaching are statistically significant.

ANOVA shown within Table 8 tests the acceptability of the regression equation for profit margin from a statistical perspective. The regression row of Table 8 shows the degree of variation that can be accounted for by the equation. The residual row of Table 8 shows the degree of variation that is not accounted for by this model. The regression sum of squares is lower than the residual sum of squares indicating that the equation is not strongly predictive of the variation in profit margin. The significance value of the F statistic is 0.702 , however because it is much greater than 0.05 , the variation explained by this model is likely due to chance. Thus, in testing this model we found that the regression equation was not a good fit for the dependent variable profit margin. 
Table 8 Coefficients, ANOVA, and Model Summary of the Regression for Profit Margin

\begin{tabular}{|c|c|c|c|c|c|}
\hline \multicolumn{6}{|c|}{ Coefficients } \\
\hline & \multicolumn{2}{|c|}{ Unstandardized } & \multicolumn{3}{|c|}{ Standardized } \\
\hline & $\mathrm{B}$ & Std. Error & Beta & $\mathrm{t}$ & $\mathrm{P}$ value \\
\hline Constant & 0.04684 & 0.044 & & 1.069 & 0.293 \\
\hline \multicolumn{6}{|l|}{ Explanatory Variables } \\
\hline Volunteerism & -0.493 & 0.302 & -0.282 & -1.630 & 0.112 \\
\hline Professionalism & -0.000885 & 0.001 & -0.114 & -0.862 & 0.395 \\
\hline \multicolumn{6}{|l|}{ Control Variables } \\
\hline$\overline{\text { Bed Size }}$ & -0.00000936 & 0.000 & -0.053 & -0.303 & 0.764 \\
\hline RN hours/FTE hours & 0.05616 & 0.096 & 0.101 & 0.585 & 0.562 \\
\hline System & 0.01011 & 0.017 & 0.106 & 0.612 & 0.545 \\
\hline Ownership & 0.004572 & 0.013 & 0.059 & 0.360 & 0.721 \\
\hline Teaching & -0.00642 & 0.014 & -0.085 & -0.468 & 0.643 \\
\hline \multicolumn{6}{|c|}{ ANOVA } \\
\hline & $\begin{array}{l}\text { Sum of } \\
\text { Squares }\end{array}$ & df & $\begin{array}{l}\text { Mean } \\
\text { Square }\end{array}$ & $\mathrm{F}$ & Sig. \\
\hline Regression & 0.006 & 7 & 0.001 & 0.663 & 0.702 \\
\hline Residual & 0.041 & 34 & 0.001 & & \\
\hline Total & 0.047 & 41 & & & \\
\hline \multicolumn{6}{|c|}{ Model Summary } \\
\hline & $\mathrm{R}$ & R Square & $\begin{array}{l}\text { Adjus } \\
\text { Square }\end{array}$ & & $\begin{array}{l}\text { Std. Error of } \\
\text { the Estimate }\end{array}$ \\
\hline & 0.356 & 0.120 & -0.061 & & 0.03473 \\
\hline
\end{tabular}


Volunteer Cost Savings

Hypothesis 3 relates to the research question, "do higher levels of volunteerism within a hospital save costs?" It hypothesizes that there is a relationship between higher levels of volunteerism and volunteer cost savings. The fourth research question asks "do higher levels of professionalism of volunteer programs within a hospital save costs?" Hypothesis 4 suggests that there is a relationship between higher levels of professionalism of volunteer programs and volunteer cost savings. The variable volunteer hours/FTE hours will be used in this equation as a measure of volunteerism.

After the removal of outliers, the $\mathrm{N}$ for this equation is 42 . Histograms and P-P plots testing the normality of this regression equation can be found in the Appendix.

Table 9 illustrates the coefficients of the regression equation for the dependent variable volunteer cost savings after the removal of the six extreme outliers. Volunteerism is clearly statistically significant and the most powerful variable even when controlling for other variables with a p-value of 0.000 and a Beta value of 0.657 , with teaching also statistically significant with a p-value of 0.022 . The unstandardized coefficient of volunteerism is positive meaning that volunteer cost savings is expected to increase as this measure of volunteerism increases, a direct relationship. The unstandardized coefficient of teaching is positive meaning that teaching status is slightly predictive of volunteer cost savings.

ANOVA, shown in Table 9 tests the acceptability of the regression equation for volunteer cost savings from a statistical perspective. The regression row of Table 9 shows the degree of variation that can be accounted for by the equation. The residual row of Table 9 shows the 
degree of variation that is not accounted for by this model. Because the regression sum of squares is equal to the residual sum of squares it can be concluded that the equation is predictive of about half of the variation in volunteer cost savings. The significance value of the F statistic is less than 0.05 , meaning that the variation explained by this model is not due to chance.

Table 9 also shows the model summary which reports the strength of the relationship between the model and the dependent variable volunteer cost savings. R, the multiple correlation coefficient is the linear correlation between the observed and model predicted values of volunteer cost savings. Its high value of 0.673 indicates a strong relationship. R square, the coefficient of determination shows that 0.453 of the variation in volunteer cost savings is explained by the model. 
Table 9 Coefficients, ANOVA, and Model Summary of the Regression for Volunteer Cost Savings

\section{Coefficients}

\begin{tabular}{|c|c|c|c|c|c|}
\hline & \multicolumn{2}{|c|}{ Unstandardized } & \multicolumn{3}{|l|}{ Standardized } \\
\hline & $\mathrm{B}$ & Std. Error & Beta & $\mathrm{t}$ & $\mathrm{P}$ value \\
\hline Constant & -0.003 & 0.100 & & -0.309 & 0.759 \\
\hline \multicolumn{6}{|l|}{ Explanatory Variables } \\
\hline Volunteerism & 0.452 & 0.099 & 0.657 & 4.557 & 0.000 \\
\hline Professionalism & -0.000364 & 0.000 & -0.206 & -1.501 & 0.142 \\
\hline \multicolumn{6}{|l|}{$\underline{\text { Control Variables }}$} \\
\hline Bed Size & -0.00000551 & 0.000 & -0.110 & -0.740 & 0.464 \\
\hline RN hours/FTE hours & 0.02001 & 0.021 & 0.128 & 0.964 & 0.342 \\
\hline System & 0.003897 & 0.003 & 0.165 & 1.278 & 0.210 \\
\hline Ownership & 0.002012 & 0.002 & 0.109 & 0.820 & 0.418 \\
\hline Teaching & 0.007919 & 0.003 & 0.377 & 2.391 & 0.022 \\
\hline \multicolumn{6}{|c|}{ ANOVA } \\
\hline & \begin{tabular}{|l} 
Sum of \\
Squares
\end{tabular} & $\mathrm{df}$ & $\begin{array}{l}\text { Mean } \\
\text { Square }\end{array}$ & $\mathrm{F}$ & Sig. \\
\hline Regression & 0.002 & 7 & 0 & 4.024 & 0.003 \\
\hline Residual & 0.002 & 34 & 0 & & \\
\hline Total & 0.004 & 41 & & & \\
\hline \multicolumn{6}{|c|}{ Model Summary } \\
\hline & $\mathrm{R}$ & R Square & $\begin{array}{l}\text { Adjusted R } \\
\text { Square }\end{array}$ & & $\begin{array}{l}\text { Std. Error of } \\
\text { the Estimate }\end{array}$ \\
\hline & 0.673 & 0.453 & 0.340 & & 0.00798 \\
\hline
\end{tabular}


Post-hoc Power Analysis

Following the regression, a power analysis was run using the statistically significant results. Table 10 below, includes the results of the power analysis using the dependent, explanatory, statistically significant control variables from the multiple regression analysis for volunteer cost savings. The alpha level for this model is 0.05 and there are four total variables including volunteer cost savings, volunteerism input, professionalism, and teaching. Using only these variables, the $\mathrm{R}$ square for the model is 0.397 . Table 10 displays evidence that this regression equation has a high power of $98 \%$.

Table 10 Post-hoc Power Analysis of Volunteer Cost Savings Regression

\begin{tabular}{l|llll} 
alpha & Number of significant variables & $R$ square & $N$ & Power (out of 1) \\
\hline 0.05 & 4 & 0.397 & 42 & 0.98
\end{tabular}

Patient Satisfaction

Hypothesis 5 is that there a relationship between higher levels of volunteerism in patient care areas and patient satisfaction. It is responding to the research question, "do higher levels of volunteerism within a hospital improve patient satisfaction?" This relationship is hypothesized to be positive. The final research question, "do higher levels of professionalism of volunteer programs within a hospital improve patient satisfaction?" Hypothesis 6 suggests that there is a relationship between professionalism of volunteer programs and patient satisfaction. The variable volunteerism input in patient settings, which measures volunteer hours in patient 
settings as a percentage of total FTE hours, will be used in this equation as a measure of volunteerism.

After the removal of outliers, the $\mathrm{N}$ for this equation is 44 . Histograms and P-P plots testing the normality of this regression equation can be found in the Appendix.

Table 11 below illustrates the coefficients of the regression equation for the dependent variable patient satisfaction. Statistically significant variables include volunteerism input in patient settings, bed size, system, and teaching. With a p-value of 0.008 , volunteerism input in patient settings is a statistically significant strong predictor of patient satisfaction even when controlling for other variables. The unstandardized coefficient of volunteerism input in patient settings is positive meaning that patient satisfaction is expected to increase as this measure of volunteerism increases, a direct relationship. The unstandardized coefficient of teaching is positive meaning that teaching status is predictive of patient satisfaction. The unstandardized coefficient of bed size is positive indicating that bed size has a slight influence over patient satisfaction. The unstandardized coefficient of system is negative, indicating that there is an inverse relationship between system membership and patient satisfaction.

ANOVA results shown in Table 11 tests the acceptability of the regression equation for patient satisfaction from a statistical perspective. The regression row of Table 11 shows the degree of variation that can be accounted for by the equation. The residual row of Table 11 shows the degree of variation that is not accounted for by this model. Because the regression sum of squares is slightly lower than the residual sum of squares it can be concluded that the equation is predictive of just less than half of the variation in patient satisfaction. The significance value of the $\mathrm{F}$ statistic is less than 0.05 , meaning that the variation explained by this model is not due to chance. 
Table 11 also reports the model summary of the strength of the relationship between the model and the dependent variable patient satisfaction. $\mathrm{R}$, the multiple correlation coefficient is the linear correlation between the observed and model predicted values of volunteer cost savings.

Its value of 0.712 indicates a strong relationship. $\mathrm{R}$ square, the coefficient of determination shows that 0.507 of the variation in patient satisfaction is explained by the model. 
Table 11 Coefficients, ANOVA, and Model Summary of the Regression for Patient Satisfaction

\begin{tabular}{|c|c|c|c|c|c|}
\hline \multicolumn{6}{|c|}{ Coefficients } \\
\hline & \multicolumn{2}{|c|}{ Unstandardized } & \multicolumn{2}{|c|}{ Standardized } & \multirow[b]{2}{*}{$P$ value } \\
\hline & $\mathrm{B}$ & Std. Error & Beta & $\mathrm{t}$ & \\
\hline Constant & 0.706 & 0.116 & & 6.113 & 0.000 \\
\hline \multicolumn{6}{|l|}{ Explanatory Variables } \\
\hline $\begin{array}{l}\text { Volunteerism Input in } \\
\text { Patient Settings }\end{array}$ & 2.631 & 0.943 & 0.368 & 2.789 & 0.008 \\
\hline Professionalism & 0.003585 & 0.003 & 0.175 & 1.310 & 0.119 \\
\hline \multicolumn{6}{|l|}{ Control Variables } \\
\hline Bed Size & 0.0001581 & 0 & 0.316 & 2.543 & 0.015 \\
\hline RN hours/FTE hours & -0.122 & 0.257 & -0.063 & -0.473 & 0.639 \\
\hline System & -0.0958 & 0.032 & -0.355 & -2.955 & 0.005 \\
\hline Ownership & 0.04452 & 0.031 & 0.186 & 1.437 & 0.159 \\
\hline Teaching & 0.122 & 0.031 & 0.500 & 3.921 & 0.000 \\
\hline \multicolumn{6}{|c|}{ ANOVA } \\
\hline & $\begin{array}{l}\text { Sum of } \\
\text { Squares }\end{array}$ & $\mathrm{df}$ & $\begin{array}{l}\text { Mean } \\
\text { Square }\end{array}$ & $\mathrm{F}$ & Sig. \\
\hline Regression & 0.265 & 7 & 0.038 & 5.279 & 0.000 \\
\hline Residual & 0.258 & 36 & 0.007 & & \\
\hline Total & 0.522 & 43 & & & \\
\hline \multicolumn{6}{|c|}{ Model Summary } \\
\hline & $\mathrm{R}$ & R Square & $\begin{array}{l}\text { Adjus } \\
\text { Square }\end{array}$ & & $\begin{array}{l}\text { Std. Error of } \\
\text { the Estimate }\end{array}$ \\
\hline & 0.712 & 0.507 & 0.411 & & 0.08463 \\
\hline
\end{tabular}


Post-hoc Power Analysis

Following the regression, a power analysis was run using the statistically significant results. Table 12 includes the results of the power analysis using the dependent, explanatory, and statistically significant control variables from the multiple regression analysis for patient satisfaction. The alpha level for this model is 0.05 and there are six total variables including patient satisfaction, volunteerism input in patient settings, professionalism, bed size, system, and teaching. Using only these variables, the $\mathrm{R}$ square for the model is 0.478 . Table 12 displays evidence that this regression equation has a high power of $99 \%$.

Table 12 Post-hoc Power Analysis of Patient Satisfaction Regression

\begin{tabular}{l|llll} 
alpha & Number of significant variables & $R$ square & $N$ & Power (out of 1) \\
\hline 0.05 & 6 & 0.478 & 44 & 0.99
\end{tabular}

$\underline{\text { Unanticipated Results }}$

The preceding data analysis produced a few unanticipated results. These related to the lack of significance found in the regression model for profit margin. This model showed no significance and none of the individual variables were statistically significant. Hence, we fail to reject null hypotheses one and two. There is not a statistically significant relationship between profit margin and volunteerism within hospitals. Furthermore, there is not a statistically significant relationship between profit margin and the professionalism of volunteer programs in hospitals. 


\section{$\underline{\text { Summary of Findings }}$}

In summary, the models testing the first and second hypotheses relating profit margin to volunteerism and professionalism were not statistically significant. Each of the variables, bed size, system, ownership, teaching, volunteerism, and professionalism displayed no significance.

The regression results for the third and fourth hypothesis relating volunteerism to volunteer cost savings were statistically significant. Volunteerism and teaching both displayed statistical significance in this model. Volunteerism was highly predictive of volunteer cost savings. Hence, we have to reject null hypothesis 3, volunteer cost savings increases with higher levels of volunteerism. Also, given the coding of the teaching variable as 1 for teaching and 0 for non-teaching the results of the analysis indicate that teaching hospitals would have slightly greater volunteer cost savings than non-teaching hospitals. Professionalism of the volunteer program was not statistically significant and therefore, the null hypothesis four must be maintained.

The regression results for the fifth hypothesis relating volunteerism in patient settings to patient satisfaction were statistically significant. Volunteerism in patient settings, bed size, system, and teaching each displayed statistical significance. Volunteerism input in patient settings has a positive impact on patient satisfaction and thus we must reject null hypothesis 5; patient satisfaction increases with higher levels of volunteerism in patient settings. Bed size is slightly predictive of patient satisfaction scores with a greater bed size increasing scores. System is coded as 1 for system and 0 for non-system facilities, thus the negative coefficient results of the analysis indicate that non-system hospitals would have slightly greater patient satisfaction scores. Again, given the coding of the teaching variable as 1 for teaching and 0 for non-teaching 
the coefficient results of the analysis indicate that teaching hospitals would also have slightly greater patient satisfaction scores. Professionalism of the volunteer program was not statistically significant and therefore, null hypothesis six must not be rejected.

Table 13 below summarizes the results of the hypothesis testing for all three dependent variables. Based on the results of the multiple linear regression analysis we reject hypothesis three and hypothesis five. The other hypotheses must not be rejected.

Table 13 Summarization of the Results of Hypothesis Testing

\begin{tabular}{|l|l|l|}
\hline \multicolumn{1}{|c|}{ Null Hypothesis } & Results & \multicolumn{1}{|c|}{ Reasoning } \\
\hline $\begin{array}{l}\text { H1: There is no relationship between } \\
\text { higher levels of volunteerism and } \\
\text { hospital profit margin. }\end{array}$ & $\begin{array}{l}\text { Fail to } \\
\text { Reject }\end{array}$ & $\begin{array}{l}\text { There was no statistically significant } \\
\text { relationship between profit margin and } \\
\text { the explanatory variable volunteerism } \\
\text { input. }\end{array}$ \\
\hline $\begin{array}{l}\text { H2: There is no relationship between } \\
\text { higher levels of professionalism of } \\
\text { volunteer programs and hospital profit } \\
\text { margin. }\end{array}$ & $\begin{array}{l}\text { Fail to } \\
\text { Reject }\end{array}$ & $\begin{array}{l}\text { There was no statistically significant } \\
\text { relationship between profit margin and } \\
\text { the explanatory variable } \\
\text { professionalism. }\end{array}$ \\
\hline $\begin{array}{l}\text { H3: There is no relationship between } \\
\text { higher levels of volunteerism and } \\
\text { volunteer cost savings. }\end{array}$ & Reject & $\begin{array}{l}\text { There was a statistically significant } \\
\text { relationship between volunteer cost } \\
\text { savings and the explanatory variable } \\
\text { volunteerism input. }\end{array}$ \\
\hline $\begin{array}{l}\text { H4: There is no relationship between } \\
\text { higher levels of professionalism of } \\
\text { volunteer programs and volunteer cost } \\
\text { savings. }\end{array}$ & Fail to & $\begin{array}{l}\text { There was no statistically significant } \\
\text { relationship between volunteer cost } \\
\text { savings and the explanatory variable } \\
\text { professionalism. }\end{array}$ \\
\hline $\begin{array}{l}\text { H5: There is no relationship between } \\
\text { higher levels of volunteerism in patient } \\
\text { settings and patient satisfaction. }\end{array}$ & Reject & $\begin{array}{l}\text { There was a statistically significant } \\
\text { relationship between patient } \\
\text { satisfaction and the explanatory } \\
\text { variable volunteerism input in patient } \\
\text { settings. }\end{array}$ \\
\hline $\begin{array}{l}\text { H6: There is no relationship between } \\
\text { higher levels of professionalism of } \\
\text { volunteer programs within a hospital and } \\
\text { patient satisfaction. }\end{array}$ & Fail to & $\begin{array}{l}\text { There was no statistically significant } \\
\text { relationship between patient } \\
\text { satisfaction and the explanatory } \\
\text { variable professionalism. }\end{array}$ \\
\hline
\end{tabular}




\section{CHAPTER FIVE: CONCLUSIONS}

\section{$\underline{\text { Conclusions }}$}

The results of the data analysis have lead to limited conclusions for this study. The first of these is that over all the results may not be generalizable to all hospitals in the state of Florida. This is primarily because in addition to other dissimilarities the study sample has a greater proportion of not-for-profit hospitals than the state. These are further discussed in the limitations of the study. However, it can be said that the results are generalizable to those hospitals that responded to the survey and because of the high percentage of respondents that were FADVS members, those hospitals in the state of Florida with a greater focus on volunteerism . This can be said due to the overwhelming proportion of respondents that are members of the Florida Association of Directors of Volunteer Services, and as members of this association are more likely to have a more significant emphasis on and concern with volunteer activity.

Conclusions regarding the hypotheses tests can also be made. The model testing the first hypothesized relationship between profit margin and volunteerism was not found to be significant and hence the first null hypothesis must be retained. This is also true of the second hypothesis regarding profit margin and professionalism of volunteer programs. The volunteer cost savings model did show significance with the variables of volunteerism and teaching and this result represents a rejection of the third null hypothesis. Also, in the model testing the fifth and sixth hypotheses, patient satisfaction was found to be significantly related to volunteerism in patient settings, bed size, system, and teaching, thus must reject the fifth and sixth null 
hypotheses. The conclusions that can be drawn based on each of these findings will be further discussed within this chapter.

The issue of external validity arises upon review of the comparison between the state's descriptive statistics and the study's descriptive statistics. While the variation in bed size, FTE, and the proportion of system hospitals are comparable between the two, there is a disproportionate number of not-for-profit facilities within the study sample. The large number of not-for-profit facilities within the study is likely to influence the results of the regression analyses.

Profit margin was not found to increase as the level of volunteerism increases. In fact, profit margin was not found to be predicted by any of the control or explanatory variables within this study including ownership. However, the literature suggests that the control variables of bed size, system, and ownership influence the profit margin or operating margin of a hospital. There are several possible explanations for this discrepancy within the study. First, the overrepresentation of not-for-profit facilities within the survey respondents may have skewed the accuracy of the regression analysis. Also, the measures used for the variables may be questionable. Finally, the theories that support the relationship between the dependent variable of profit margin and the other variables may not be well suited for this study. Each of these possibilities will now be further discussed.

The profile of hospitals within the state of Florida suggests that most of them are part of a for profit healthcare system. This means that they are investor owned and run. In contrast, the profile of hospitals within the study suggests that most are members of not-for-profit healthcare systems. While they do not seek a profit, these facilities are able to calculate an operating margin which was used as a measure of profit margin in this study. Logically, one would 
assume that for profit facilities actively seeking a profit are likely to have greater operating margins than not-for-profit facilities. Hence, the not-for-profit facilities that largely dominate the study sample may have reduced the measure of profit margin as well as the range of profit margin within the sample. In turn, the significance of the model as a predictor for profit margin may have been reduced.

The second scenario explaining the reasons for the insignificant results of the profit margin regression suggest that some of the measures used as dependent, explanatory and control variables, especially those that were calculated or related to volunteerism, for this study may have been inadequate. However, it is important to note that if the variables were in fact inadequate in the profit margin regression, they would also be inadequate in the other regressions as well. Table 5 defines each of the variables for the study and their data sources. Many of these variables are straightforward measurements such as the control variables of bed size, FTE, system, ownership, and teaching. Others had to be calculated including profit margin, volunteer cost savings, volunteerism, and professionalism of the volunteer program. While all of this information was collected in the survey, only some of the variables were able to be verified by other data sources such as the AHCA financial data and AHA annual survey for 2004. Those that were verified included profit margin using operating revenue and operating expenses from the AHCA data files; and bed size, FTE, and ownership using AHA data. The operating expenses in the AHCA data file was also used as the total budget denominator in the calculations for volunteer cost savings. Similarly, the FTE numbers from the AHA dataset were used in the volunteerism measurements. The use of ratios in these measures was supported by the literature as a mechanism to account for size. Information about the volunteer programs and the patient satisfaction scores could not be verified. 
Hence, inaccuracy in the collected data is a possibility. Furthermore, the survey instrument may not have been sufficient in developing an accurate depiction of a hospital's level of volunteerism. Again, insufficiency in the survey would affect all of the regression results. The instrument was not field tested and previous literature did not exist on this type of survey the development of the survey, relied upon the expertise of the FADVS board members. Initially, a survey previously developed by FADVS to assess the volunteer programs of their member hospitals served as a skeleton for this survey. The survey was reviewed during subsequent meetings with the board which allowed for further revisions to be made to the instrument so that it would better serve the needs of this study.

Organizational performance theory, production theory, and Donabedian structureprocess-outcome theory each provided a theoretical framework for this study. All three of these theories offer perspectives on profit margin, the regression in question. They also can relate production and outcomes to volunteerism. For instance, organizational performance theory suggests productivity and efficiency as essential goals for a successful organization. Profit margin can be considered a measure of both productivity and efficiency. It can also be suggested that volunteers are a source of input, a highly efficient input, which can impact the productivity of an organization. Similarly, production theory analyzes the inputs and outputs of an organization, including their labor inputs. Again, volunteers are a specific type of labor input influencing the production of the organization. Finally, Donabedian structure-process-outcomes theory suggests that organizational performance be determined by its structure, process, and outcomes. The presence of a volunteer program and volunteers themselves impact the structure of the organization thereby influencing the process and outcomes. In this case one of those outcomes could be considered the hospital's profit margin. Each of these theories frames 
sensible expectations for the relationship between profit margin and volunteerism, however, none of these theories are specifically intended for studies on volunteerism and therefore they may not have been a perfect fit for this study. A fourth and final reason for the failure of the volunteerism variable to impact the profitability measure may be that it simply does not have a very large affect on profit. It impacts quality and the patient experience, but does not generate revenue.

While the study showed no statistically significant relationship between profit margin and volunteerism, other hypotheses were supported by the data analysis. Volunteer cost savings was found to increase as the level of volunteerism increases. In fact, the level of volunteerism was found to be a strong predictor of volunteer cost savings within the model, with a Beta value of 0.452. As suggested throughout the literature, including Handy and Srinivisan (2004), Wells et. al. (1990), The Independent Sector, Kentner (2003), Christian (2007) and others, this result provides empirical evidence that while there are costs associated with volunteer programs, the financial benefits of the programs within those hospitals that participated in the study exceed the cost. Within the study sample it can be concluded that the greater the level of volunteerism, meaning the greater the number of volunteer hours, the greater the benefit to the hospital. Many of the programs reported savings of over a million dollars regardless of the hospital size, suggesting that this benefit is likely to be true of any hospital with a significant focus on volunteerism.

The teaching status of those hospitals that responded to the survey the hospital was also found to be statistically significant to their volunteer cost savings. The teaching status of a hospital was found to be predictive of volunteer cost savings with a Beta value of approximately 0.008. Because this variable was coded as 1 for a teaching hospital and 0 for a non teaching 
hospital, this result suggest that the teaching hospitals that participated in the study are likely to show an increase in volunteer cost savings. This relationship may be explained by the use of students in these facilities. Students are generally paid less than other health care providers and hence they may be saving the facility money. Furthermore, students may frequently become involved in the volunteer programs of teaching facilities as a gateway for them to become further involved in the organization.

The fifth hypothesis of this study was also supported by the data analysis. Patient satisfaction scores of those hospitals that responded to the survey were shown to improve as the level of volunteerism in patient settings, study participants and other hospitals with a significant volunteer component are likely to successfully improve their patient's experiences. These results illustrate that the utilization of volunteers in patient settings will greatly impact the patient experience. Some of the settings that were included in this measure were non-care areas such as admissions or transportation. The results suggest that volunteers used in these areas can greatly impact the patient experience even if they are not directly influencing their care. This finding is supported throughout the literature including articles written by Wells et. al. (1990), Connors (1995), Allen (2006), Wolford (1995) and others whom discussed not only the impact that volunteers make on the experience of hospital patients but also hospice and nursing home residents. Also, despite the rejection of the hypothesized relationship between patient satisfaction and professionalism of the volunteer program, those hospitals that ranked highest on the professionalism index were more likely to have patient satisfaction scores within the $95^{\text {th }}$ percentile. While this relationship was not found to be statistically significant the survey data suggests that within the study sample, a well developed volunteer program will make an impact on the patient experience. 
Other variables, bed size, system and teaching status, in this study were found to be significantly predictive of a hospital's patient satisfaction scores. Within the study sample, bed size is slightly predictive of patient satisfaction scores, with a Beta value of approximately 0.0002. On the other hand, the Beta value of -0.0958 suggest that for those hospitals that responded to the survey, system membership has an indirect relationship with patient satisfaction scores. This variable was coded as 1 for system members and 0 for non system hospital facilities; the negative coefficient suggests that the non system facilities within this sample are likely to have improved scores. The most probable explanation for this is that hospitals within a system are likely to have a focus on more system wide goals such as financial outcomes rather than patient satisfaction scores. Furthermore, the plans in place for the overall system may not be well suited for the individual hospitals. Those responding hospitals designated as teaching hospitals illustrated a statistically significant relationship with patient satisfaction scores, with a Beta value of 0.122 . Because teaching status is coded as 1 for teaching hospitals and 0 for non teaching facilities this result indicates that within those hospitals that responded to the study and those with more significant volunteer activity, teaching hospitals are likely to have higher patient satisfaction scores. This may be because teaching hospitals rely on and instruct students and are more likely to stress the importance of patient satisfaction to these students. Moreover, students are less likely to have developed negative habits and are in the process of developing strong bedside manner leaving a positive impression on the patient. Also, adding students to the mix of healthcare professionals, likely increases the face time that patients have with individuals because the students act as an additional helping hand for the patient. 


\section{$\underline{\text { Limitations }}$}

One limitation to the study is based on whether or not the results are externally valid, or generalizable to the state of Florida. Table 4 previously shown in the survey sample section of the paper (p. 37), compares the descriptive statistics of bed size, RN hours/FTE hours, system, and ownership for the state of Florida to the descriptive statistics of these variables within the study sample.

The mean or percentage for the hospitals in the sample was significantly different for all five comparison variables above. This dissimilarity was not unexpected since it was expected that FADVS members and other hospitals with a significant volunteer program component would be overrepresented among the respondents because these hospitals would naturally have greater interest in the study results. Moreover, since FADVS membership was positively correlated with bed size, not for profit ownership, and teaching hospital status a higher response rate among hospitals with these characteristics was also expected.

Consequently the results should not be generalized to all Florida hospitals. Rather, they should be generalized to larger, non-profit, teaching, and FADVS member hospitals.

Based on Table 4, all five variables that were compared are dissimilar between the hospital universe and the study sample. Ownership in the study is overrepresented with a greater proportion of not-for-profit hospitals and FADVS membership is also overrepresented in the study. Most of the participants were also not-for-profit hospitals. The majority of the participants are part of a larger organizational system. The differences between the study sample and all hospitals within the state are further illustrated by the one sample t-test and chi-square non-parametric test found in Table 4 which was previously shown in the survey sample section 
of the paper. Because of the differences in all five variables between the state and the study sample the sample is considered dissimilar from Florida as a whole and the survey respondents are not representative of the hospital universe.

The professionalism of the volunteer programs within the participating hospitals also showed a great deal of variation ranging from a low score of 9 to a high score of 34 out of 34 , achieved by one facility. More details on this variable are available in the Appendix.

Despite the differences in the study sample and the population of hospitals within the state of Florida it is important to note that this is not a fatal flaw of the study. This is because the results are not being generalized to all Florida hospitals since many (i.e. small and for-profit hospitals) do not have a fully-developed volunteer component and were underrepresented among the respondents as expected. Rather, the goal of this study is to generalize the results to those hospitals that responded to the survey and those with a significant volunteer component.

A second limitation of the study is related to the ability of study participants to accurately complete the survey. The survey was sent to Directors or Managers of Volunteer Services departments. These individuals may not have had complete access to data within their facility and may have used estimates to complete the survey. As the surveyor, it was not evident when or if estimates were used. To reduce this limitation AHA and AHCA data were used to verify a large number of survey data. However, AHA and AHCA data sets do not have data on volunteer programs and cannot be used to verify answers related to the volunteer programs. Another possibility is that some of the participants may not have felt comfortable using an estimate and may have left a question unanswered. For the most part however, surveys were either very complete or very incomplete with few questions left blank. Yet a third scenario is that they simply may not have wanted to release any information without further understanding of the 
study. To reduce these occurrences, the participants were provided with an informed consent sheet explaining the purpose of the study and the confidentiality of the data being provided. This sheet also provided them with contact information in the event that they had any questions. Follow up phone calls and e-mails were made in an effort to reduce unanswered questions. If surveys remained incomplete after such efforts were made they were not used in the data analysis.

Finally, the study is limited in that it was unable to include the patient safety dependent variable in the final analysis because data on this measure was not available. Initially, the survey that was distributed to volunteer managers across the state of Florida included a question on the number of adverse events that occurred in 2004 in their facility. However, after hearing from several concerned directors of volunteer services about the sensitivity of this data or their inability to obtain and release it; that question was removed from the survey. Other possible data sources including AHCA data were considered as alternatives for obtaining this data but AHCA data on adverse events was aggregated at the state level. While patient level administrative data is available through AHCA Hospital Inpatient Data, and this data can be used to extract adverse events from the patient discharge record, such an extraction requires the use of complicated algorithms or sophisticated software from the Agency for Healthcare Research Quality Patient Safety Indicators and is very time-consuming (Patient Safety Indicators Overview, 2006).

\section{Policy Implications}

A number of policy implications can be made based on the conclusions of this study.

First, a great deal of information about 50 hospitals and their volunteer programs was collected. 
From this information it became evident that volunteer programs vary among hospitals. As evidenced by the variation in professionalism scores, their management, budget, size, service assignments, policies, processes and methods do not appear to be closely monitored or regulated. Based on the belief that a relationship exist between the professionalism of a volunteer program within hospitals with significant volunteer activity and patient satisfaction, a need for monitoring of the programs becomes apparent.

State and local regulation of volunteer programs would allow for consistency across the realm regardless of a hospital's classification or size. Regulations could also be formulated by associations such as FADVS or the Florida Hospital Association. Furthermore, accrediting organizations could begin to monitor volunteer programs. Recruitment methods, screening and interviewing techniques, orientation and training, policies, service guidelines, and risk management plans each contribute to the formalization and professionalism of the volunteer program. Implementing regulatory policies in each of these areas will not only standardize volunteer programs but it will allow for improvements of current programs. Mook, Handy, and Quarter (2007) also noted the need for regulation on the reporting of volunteer value in financial statements. Because record keeping seems to vary at the organizational level, such regulation would simplify research studies such as this one and standardize estimations of volunteer value (Mook et. al., 2007). Furthermore, standards will allow for monitoring of progress and implementation of quality improvement initiatives for volunteer programs.

As evidenced by the results of the data analysis, within the study sample, increasing the number of service assignments of volunteers in patient settings as a result of monitoring or regulating could also raise patient satisfaction scores. The growing number of healthcare providers and health delivery mechanisms has created an environment in healthcare that is 
extremely competitive. In order to be productive and perform well, hospitals must maintain and grow their customer base. These customers include the patients and their families whom may respond to patient satisfaction surveys. Modern day healthcare consumers have many choices and options when they seek care and there are many influential factors in their selections, but none are likely to be weighted nearly as heavily as a recommendation from a friend or family member.

The empirical relationship found within study participants between volunteer cost savings and volunteerism also leads to policy suggestions which can be applied to hospitals with a focus on volunteerism. Because the measure for volunteerism in this regression considered the number of volunteer hours/FTE hours rather than the number of volunteers/number of FTEs it suggests that volunteer hours rather than volunteer volume can save hospitals significant amounts of money. In other words, a hospital of 200 full time employees with a volunteer program with 50 volunteers who each volunteer an average of 10 hours a week will experience greater volunteer cost savings than if that hospital's volunteer program had 200 volunteers who only volunteer an average of 2 hours per week. These observations lead to the logical conclusion that within the specified hospital population, volunteer hours can replace a certain amount of paid FTE hours and that when volunteers give their time they are doing work that otherwise would have to be compensated. Because quality was not controlled for in this equation, it is not known whether lower costs with greater volunteer hours would be at the expense of lower quality.

To maximize the benefit of volunteer cost savings, volunteer programs should carefully screen volunteers before selecting them. Policies should be in place requiring a minimum time commitment from volunteers. Because there are costs involved in the management of the volunteer program and in the recruitment, selection, and training of volunteers, it is important to 
only spend these dollars on volunteers that are willing and able to commit their time. This is especially important for small programs with a limited budget for their volunteers. Some hospitals within the study even reported that there was no budget allocated to the volunteer program and that the program was entirely self run by volunteers meaning that there were no salaried employees managing it. Others were managed by a salaried employee but this task was not the employee's primary job responsibility. With the careful selection of volunteers and the implementation of time commitment policies even these programs will reap volunteer cost savings for their hospitals. Of course, the allocation of funds to such efficient programs will only amplify the volunteer cost savings benefit to the hospital.

Based on the statistical evidence of relationships among the variables of teaching status and system status with the volunteer cost savings and patient satisfaction variables within this study further policies should be considered. Teaching status was found to be positively related to patient satisfaction and volunteer cost savings at those hospitals that responded to the survey. Respondent hospitals that are part of a larger system were found to have reduced patient satisfaction scores. This suggests that non-teaching hospitals may need to create policies that will allow them to continue to operate efficiently without sacrificing the quality of care they provide. Similarly, healthcare systems must provide resources and policy guidelines that will enhance patient satisfaction scores at their affiliated hospitals.

\section{$\underline{\text { Recommendations for Future Research }}$}

This study is significant in that it found empirical evidence of a positive relationship between volunteerism and cost savings and volunteerism and patient satisfaction. Yet, the 
results and policy implications suggest a need for further research. This is especially true in that the results of the regression analysis performed in this study to determine the existence of a relationship between profit margin and volunteerism was insignificant.

Future research is needed to determine whether a relationship exists between profit margin and volunteerism and to discover the degree to which volunteerism influences profit margin. Organizational performance theory, production theory, and Donabedian structureprocess-outcome theory each imply that volunteers should enhance performance. Thus, a direct positive relationship between these variables is expected; however there is no empirical evidence of such a relationship. To avoid the issues experienced by this study, future research should carefully select a sample that includes a variety of hospital types. Careful selection of study variables and their measure is also essential to the quality and outcomes of this research.

The study population for this future research could be expanded to include hospitals throughout the United States rather than just in Florida. Experts in the field of volunteerism should be contacted and interviewed to determine the best measures of volunteerism. Furthermore, structural equation modeling should be used to analyze the data and better determine study variables. Qualitative research may also be helpful in the identification of best practices and creation of future volunteer policy.

In addition to researching the profit margin dependent variable, future research is needed to further explore the relationships that exist between volunteerism and cost savings and volunteerism and patient satisfaction. This study supports the theoretical belief that volunteers can increase volunteer cost savings for hospitals. Future research should focus on mechanisms that could enhance this relationship so that the benefit is maximized. It should also determine 
whether this relationship can exist in any hospital and how it can be implemented in nearly every hospital in the United States.

Likewise, this study suggests that the use of volunteers in patient settings can enhance a hospital's patient satisfaction scores. Future research further exploring the relationship between these variables and focusing on the development of this relationship could greatly benefit hospitals wishing to increase their competitiveness in regards to patient satisfaction. This research should also focus on policy that will maximize the use of volunteers so that they can make a greater impact on the patient experience.

Because of the many challenges involved in the obtainment of data on volunteer programs, future researchers would likely benefit from collaborating with professional associations of hospital CEOs. Possible associations to pursue in such collaborative efforts include the American College of Healthcare Executives and state hospital associations such as the Florida Hospital Association. Member CEOs would be able to persuade their directors of volunteer programs to participate in the study, assisting in the procurement of data on volunteerism. Furthermore, the American Hospital Association should collect data on hospital volunteer programs in their annual survey. This would exponentially increase the opportunities for future research in this area.

Because teaching and system status were both shown to be statistically predictors in this study, research on the relationship of these variables to volunteer cost savings and patient satisfaction should be conducted. Teaching status displayed a positive relationship to volunteer cost savings and a positive relationship to patient satisfaction. Future research is needed to determine the causes of these relationships and whether they can be enhanced. System membership was shown to have a negative relationship with patient satisfaction. Further 
research is necessary to determine whether this outcome is true for a majority of system hospitals regardless of their other characteristics. This research should also focus on methods of reducing or reversing this outcome as hospital members of healthcare systems are likely to continue to become the norm.

Finally, the difficulty in obtaining data on adverse events resulted in the removal of a dependent variable in this study. However, findings of empirical evidence of a relationship between volunteerism and patient safety are both interesting and important and should be considered for future research. In order to obtain data on adverse events, which is often considered highly confidential and sensitive, researchers will need to work with the organizations to better market the benefits of participating in a survey. Again, working with CEOs or other administrators is likely to influence the cooperation of a hospital to participate in the data collection. Hospitals are moving into an era of greater transparency and while some resistance is likely, the release of such data to researchers would be beneficial not only for research purposes but also to enhance hospital operations as the result of such research. Furthermore, researchers can obtain data on pertinent adverse events at the facility level if they are familiar with the conversion of State Inpatient Databases utilizing AHRQ's Patient Safety Indicators Download and are able to successfully extract the data and link it to the individual hospital using state identifiers (Patient Safety Indicators Overview, 2006). 


\section{APPENDIX A: FLORIDA VOLUNTEERISM SURVEY}




\section{A. Hospital Grouping Information in 2004}

Please use data at the hospital rather than the system level. If you work for a system that includes multiple hospitals please fill out a survey for each individual hospital.

1. Name of Hospital *:

\begin{tabular}{|c|c|c|c|c|c|}
\hline $\begin{array}{l}2 . \\
\text { Licensed } \\
\text { Beds } 2004\end{array}$ & $\begin{array}{l}\text { 3. Annual RN } \\
\text { FTEs } 2004\end{array}$ & $\begin{array}{l}\text { 4. Teaching } \\
\text { Status } 2004\end{array}$ & $\begin{array}{l}\text { 5. Ownership } \\
2004\end{array}$ & $\begin{array}{l}\text { 6. Annual } \\
\text { Paid FTEs } \\
\text { 2004 }\end{array}$ & $\begin{array}{l}\text { 7. System } \\
2004\end{array}$ \\
\hline & & $\begin{array}{ll}\square & \text { Non-teaching } \\
\square & \text { Teaching }\end{array}$ & $\begin{array}{ll}\square & \text { Not-for-Profit } \\
\square & \text { Investor-Owned } \\
\square & \text { Public/Government }\end{array}$ & & $\begin{array}{ll}\square & \text { Non-system } \\
\square & \text { System }\end{array}$ \\
\hline
\end{tabular}

\section{B. Performance Information in 2004}

Please use data specific to the hospital level rather than the system level.

\begin{tabular}{|l|l|l|}
\hline $\begin{array}{l}\text { 8. Profit Margin } \\
2004\end{array}$ & $\begin{array}{l}\text { 9. Overall Rating of Care by } \\
\text { Patients 2004 (indicate Press } \\
\text { Ganey or other) }\end{array}$ & 10. Total Hospital Budget \\
\hline & Score: & \\
\hline & Type: & \\
\hline
\end{tabular}

C. Volunteer Information in 2004

Please use data specific to the hospital level rather than the system or auxiliary level.

\begin{tabular}{|c|c|c|}
\hline $\begin{array}{l}\text { 11. Written Volunteer } \\
\text { Policies in } 2004 \text { (check all } \\
\text { that apply) }\end{array}$ & $\begin{array}{l}\text { 12. Written Volunteer Service } \\
\text { Guidelines in } 2004 \text { (check those } \\
\text { that exist) }\end{array}$ & $\begin{array}{l}\text { 13. Volunteer Savings } 2004 \\
\text { (volunteer hours } x \text { average } \\
\text { hourly rate of } \$ 18 \text { ) }\end{array}$ \\
\hline$\square \quad$ Confidentiality Policy & Auxiliary Member & \\
\hline$\square \quad$ Conflict of Interest Policy & $\square \quad$ Fund Raising Committee & \\
\hline Recruitment and Selection & $\square \quad$ Professional Service Volunteer & \\
\hline Assignment Policy & Policy Volunteer & \\
\hline Oversight / Evaluation & Generic Service Volunteer & \\
\hline$\square \quad$ Job Description Policy & $\square \quad$ Greeters & \\
\hline Orientation Policy & $\square \quad$ Transporters & \\
\hline$\square \quad$ Rights and Responsibility & $\square \quad$ Clerical & \\
\hline$\square \quad$ Risk Management Policy & $\square \quad$ Other: & \\
\hline Safety Policy & $\square \quad$ Other: & \\
\hline$\square \quad$ Infection Control Policy & $\square \quad$ Other: & \\
\hline$\quad$ Disciplinary Policy & & \\
\hline
\end{tabular}




\section{Volunteer Information in 2004 (continued)}

Please use data specific to the hospital level rather than the system or auxiliary level.

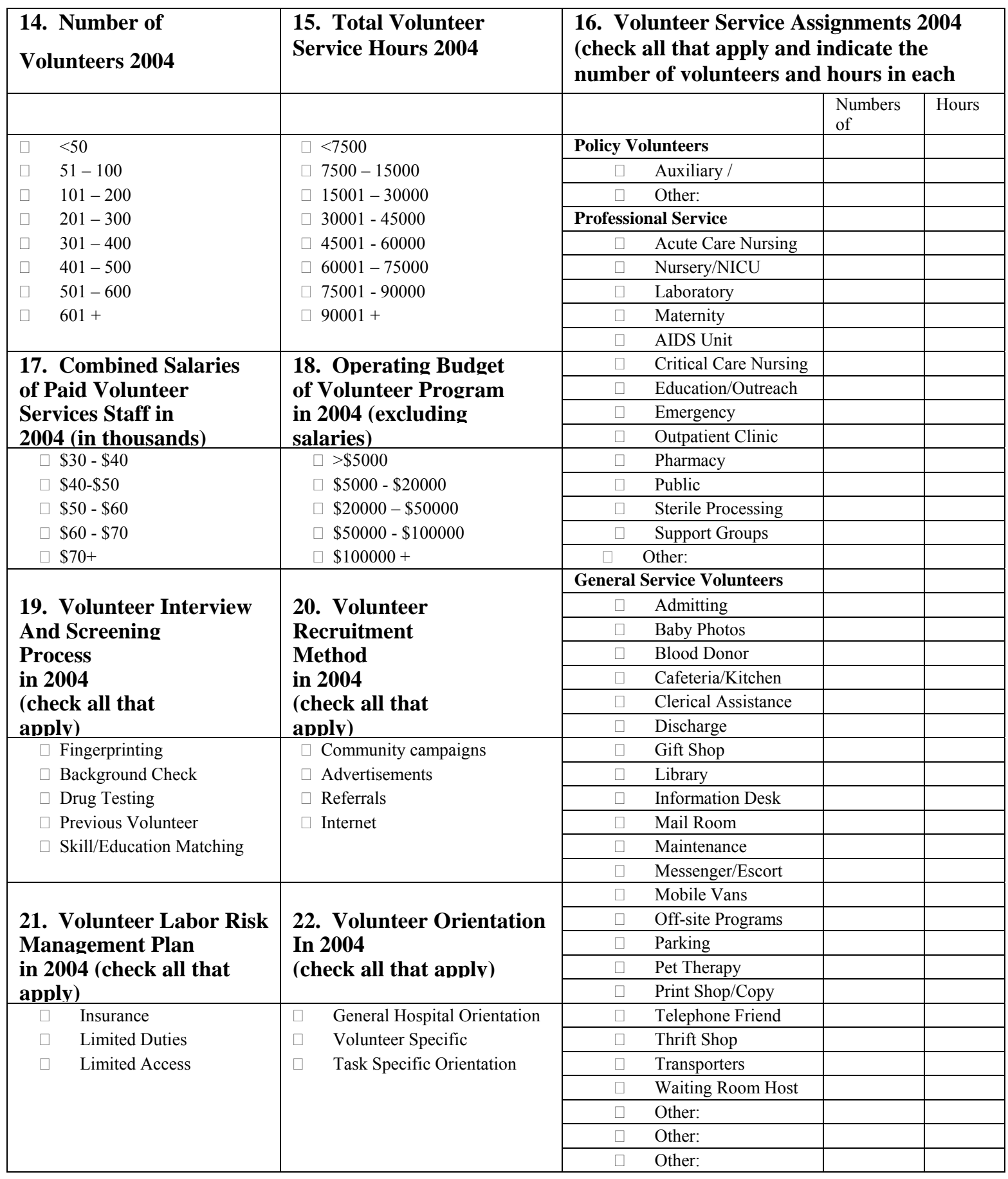

* Name will be held confident and will only be used to match information reported on this survey to public information about the facility. 
APPENDIX B: PRESS GANEY SURVEY 


\begin{tabular}{|lll}
\hline I. PHISICIAN & very & very \\
poor poor fair good good
\end{tabular}

1. Time physician spent with you

$\begin{array}{llllll}1 & 2 & 3 & 4 & 5\end{array}$

2. Physician's conceen for your questions and wories ............................ $1 \begin{array}{llllll}1 & 2 & 3 & 4 & 5\end{array}$

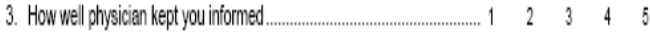

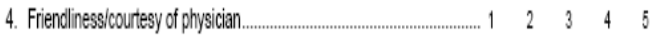

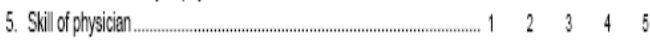

Comments (describe good or bad excerience):

\begin{tabular}{llr}
\hline \hline J. DISCHARGE & very & very \\
poor poor tair good good
\end{tabular}

1. Extent to which you fett ready to be discharged.............................. $1 \begin{array}{lllll}1 & 2 & 3 & 4 & 5\end{array}$

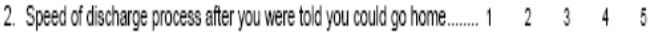

3. Instructions given about how to care for yourself a thome..................... $\begin{array}{llllll}1 & 2 & 3 & 4 & 5\end{array}$

4. Hep with aranging home care services (if needed) .............................. $1 \begin{array}{lllll}1 & 2 & 3 & 4 & 5\end{array}$

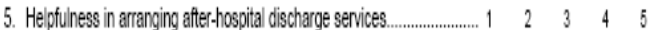

Comments (describe good or bad experience):

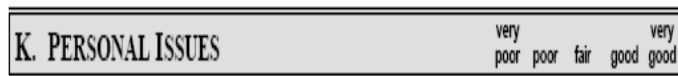

1. Staff concem for your privacy $\begin{array}{lllll}1 & 2 & 3 & 4 & 5\end{array}$

2. Staff sensitvity to the inconvenience that heath problems and hospitalization can cause

$\begin{array}{lllll}1 & 2 & 3 & 4 & 5\end{array}$

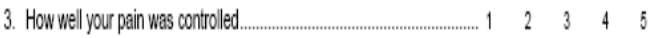

4. Degree to which hospital staff addressed you emotionallspiritual needs $1 \begin{array}{lllll}1 & 2 & 3 & 4 & 5\end{array}$

5. Response to concerns complaints made during your stay..................... $1 \begin{array}{llllll}1 & 2 & 3 & 4 & 5\end{array}$

6. Staff effort to include you in decisions about your treatment ................. $1 \begin{array}{lllll}1 & 2 & 3 & 4 & 5\end{array}$

Comments (describe good or bad experience):

\begin{tabular}{llr}
\hline \hline L. OVERALL ASSESSIIENT & very & very \\
poor poor fair good good
\end{tabular}

1. Overall cheerfuness of the hospotal .............................................. $\begin{array}{lllllll}1 & 2 & 3 & 4 & 5\end{array}$

2. How well staff worked together to care for you ............................ $\begin{array}{llllll}1 & 2 & 3 & 4 & 5\end{array}$

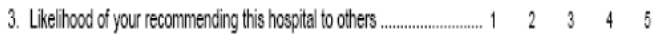

4. Overal reating of care given at hospital .................................. $1 \begin{array}{lllll}1 & 2 & 3 & 4 & 5\end{array}$

Comments (describe good or bad experience):

Patient's Name: (ootional)

Telephone Number. (optiona)

Q 2020 PRESS GWEE ASSOCHTES, NC

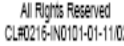

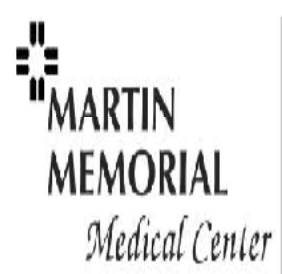

\section{INPATIENT SURVEY}

We thank you in advance for completing this questionnaire, When you have finished, please mail itin the enclosed envelope.

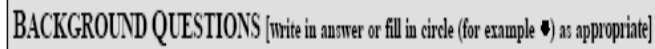

\begin{tabular}{|c|c|}
\hline 1. Patien's first stay here......... O Yes $O$ No & $\begin{array}{l}\text { 10. Main source of payment for hospita stay. } \\
\text { (filin none erclib onyy) }\end{array}$ \\
\hline $\begin{array}{l}\text { 2. Admitted through the } \\
\text { Emergency Deparment...... O Yes O No }\end{array}$ & $\begin{array}{l}\text { O Private Insurance } \\
\text { O Medicare } \\
\text { O Medicaid }\end{array}$ \\
\hline $\begin{array}{l}\text { 3. Was your admission } \\
\text { unexpected?................ O Yes ONo }\end{array}$ & $\begin{array}{l}\text { O Worker's Compensation } \\
0 \text { Self-pay }\end{array}$ \\
\hline
\end{tabular}

4. Did you have a roommate? ... O Yes $O$ No

11. Room number.

5. Were you placed on a

special or restricted diet

during most of your stay?.... O Yes Q Q No

12. Number of days in hospital

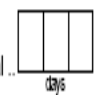

6. Did someone explain your

extended life support

(e.g., living vill, advance

directives, etc. Ootions?...... O Yes O No

13. Date of discharge:

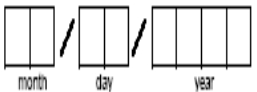

7. Did someone give you

in'ormation about organ

donation?

... O Yes ONO

8. Did someone give you

information about the

Patients Bill of Rights? ....... O Yes O No

9. Do you have insurance

that limits your choice of

physician or provider

(e.g.) HMO or PPO)?

OYes ONO

14. Patien's sex......... OMale OFemale

15. Patient's age

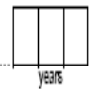

16. Compared to others your age, how would you typically describe you health? (cricleonenumber)

$$
\begin{array}{ccccc}
\text { very } & & & \text { very } \\
\text { poox } & \text { poor } & \text { tair } & \text { good } & \text { good } \\
1 & 2 & 3 & 4 & 5
\end{array}
$$




\section{APPENDIX C: PROFESSIONALISM INDEX}




\begin{tabular}{|c|c|c|c|c|c|}
\hline \multicolumn{6}{|c|}{ Professionalism } \\
\hline & & Frequency & Percent & Valid Percent & $\begin{array}{c}\text { Cumulative } \\
\text { Percent }\end{array}$ \\
\hline \multirow[t]{22}{*}{ Valid } & 9.00 & 2 & 4.0 & 4.0 & 4.0 \\
\hline & 12.00 & 1 & 2.0 & 2.0 & 6.0 \\
\hline & 13.00 & 1 & 2.0 & 2.0 & 8.0 \\
\hline & 14.00 & 1 & 2.0 & 2.0 & 10.0 \\
\hline & 15.00 & 2 & 4.0 & 4.0 & 14.0 \\
\hline & 16.00 & 1 & 2.0 & 2.0 & 16.0 \\
\hline & 17.00 & 3 & 6.0 & 6.0 & 22.0 \\
\hline & 18.00 & 3 & 6.0 & 6.0 & 28.0 \\
\hline & 19.00 & 2 & 4.0 & 4.0 & 32.0 \\
\hline & 20.00 & 5 & 10.0 & 10.0 & 42.0 \\
\hline & 21.00 & 5 & 10.0 & 10.0 & 52.0 \\
\hline & 22.00 & 3 & 6.0 & 6.0 & 58.0 \\
\hline & 23.00 & 3 & 6.0 & 6.0 & 64.0 \\
\hline & 24.00 & 1 & 2.0 & 2.0 & 66.0 \\
\hline & 25.00 & 3 & 6.0 & 6.0 & 72.0 \\
\hline & 26.00 & 4 & 8.0 & 8.0 & 80.0 \\
\hline & 27.00 & 2 & 4.0 & 4.0 & 84.0 \\
\hline & 28.00 & 4 & 8.0 & 8.0 & 92.0 \\
\hline & 29.00 & 2 & 4.0 & 4.0 & 96.0 \\
\hline & 32.00 & 1 & 2.0 & 2.0 & 98.0 \\
\hline & 34.00 & 1 & 2.0 & 2.0 & 100.0 \\
\hline & Total & 50 & 100.0 & 100.0 & \\
\hline
\end{tabular}

\section{Professionalism}

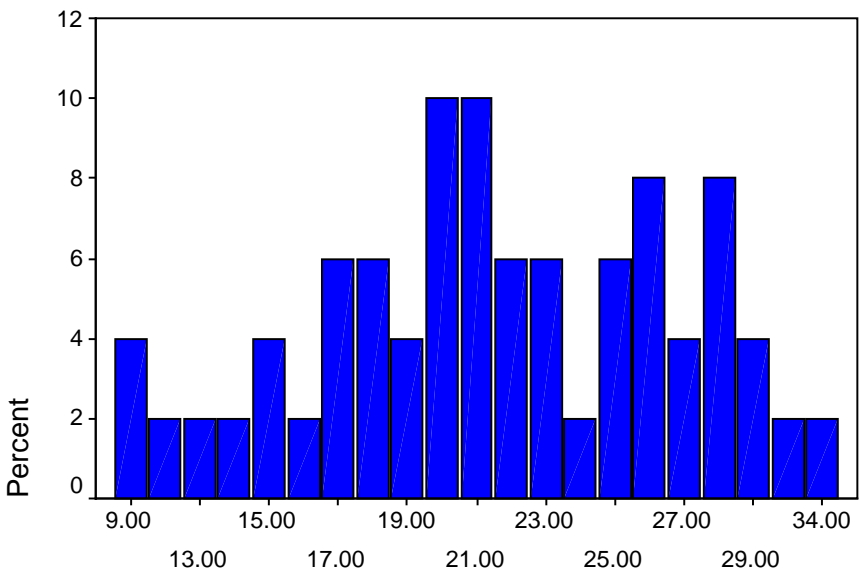

Professionalism 
APPENDIX D: BOX PLOT OF COOK'S DISTANCE FOR PROFIT MARGIN 


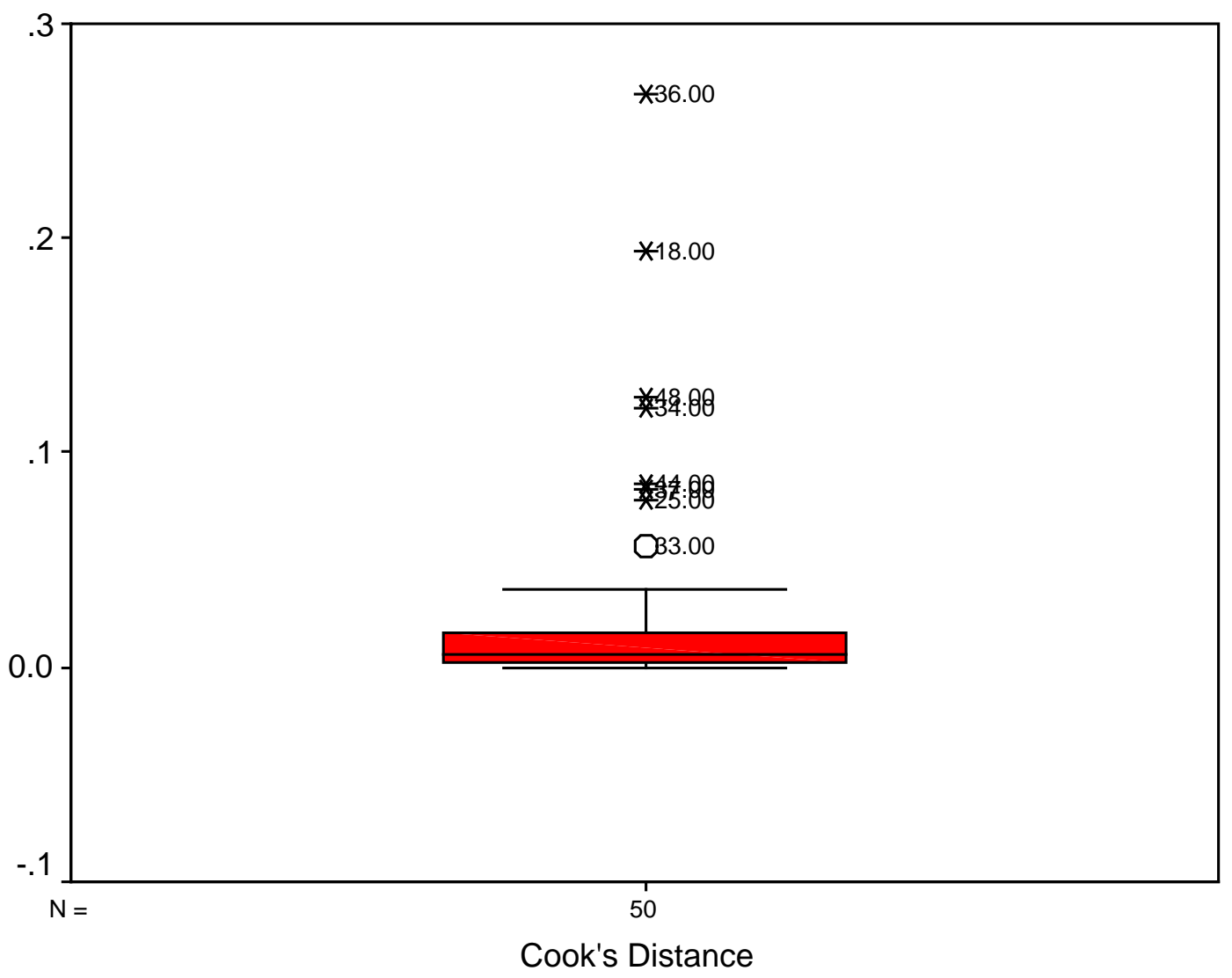


APPENDIX E: BOX PLOT OF COOK'S DISTANCE FOR VOLUNTEER COST SAVINGS 


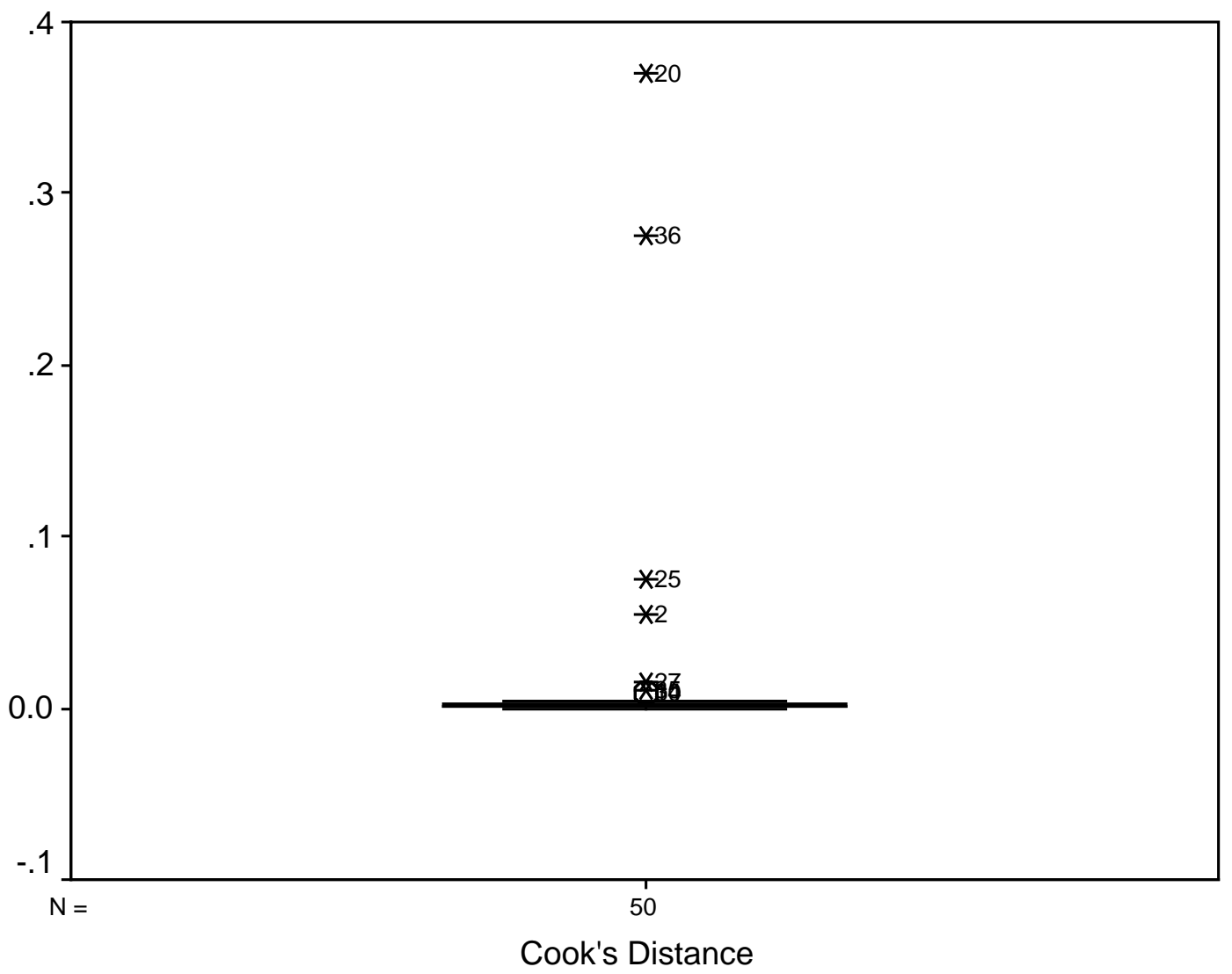




\section{APPENDIX F: BOX PLOT OF COOK'S DISTANCE FOR PATIENT}

SATISFACTION 


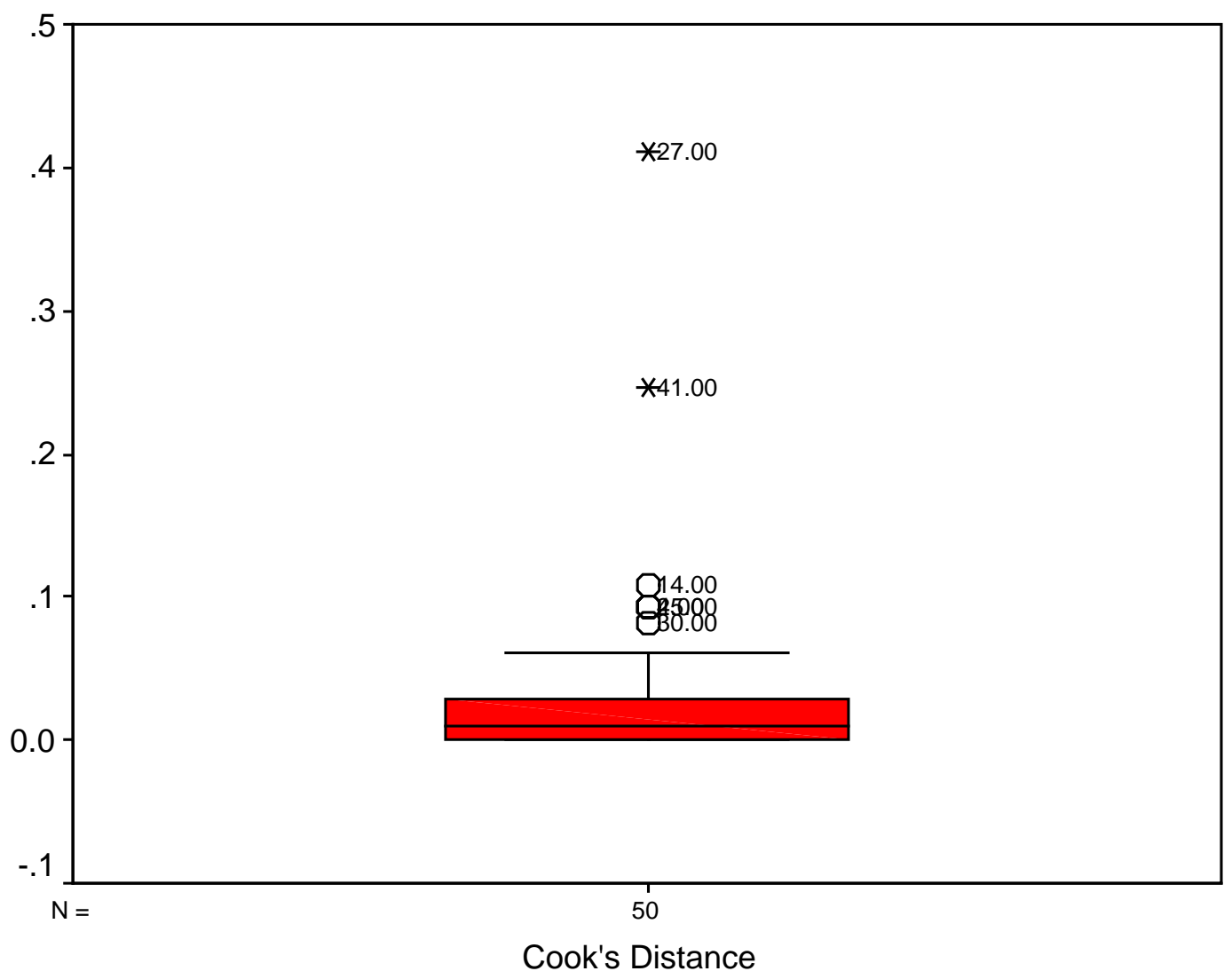




\section{APPENDIX G: NORMALITY OF PROFIT MARGIN REGRESSION}

EQUATION 
The histogram below can be used to indicate the assumption of normality of the error term. Because the shape of the histogram closely follows the shape of the normal curve it can be determined that the normality is acceptable. Furthermore, the P-P plot below follows the 45 degree line indicating that normality can be assumed.

Histogram

Dependent Variable: Profit Margin

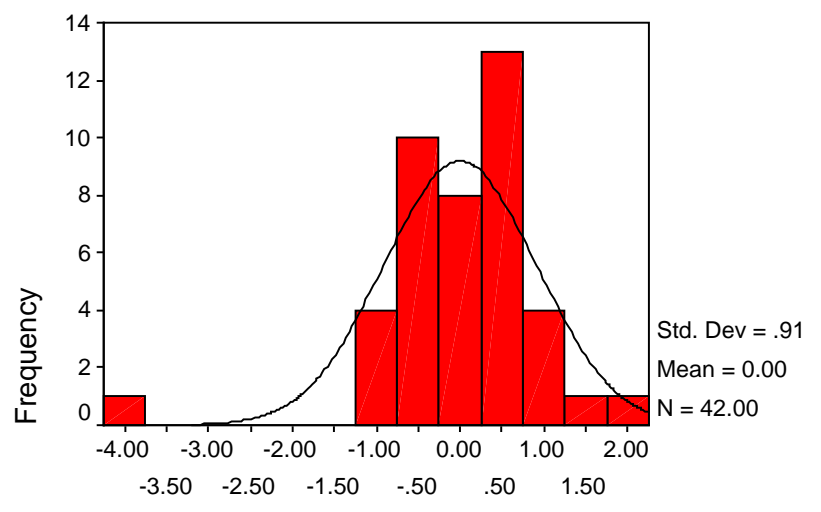

Regression Standardized Residual

Normal P-P Plot of Regression Standardized

Dependent Variable: Profit Margin

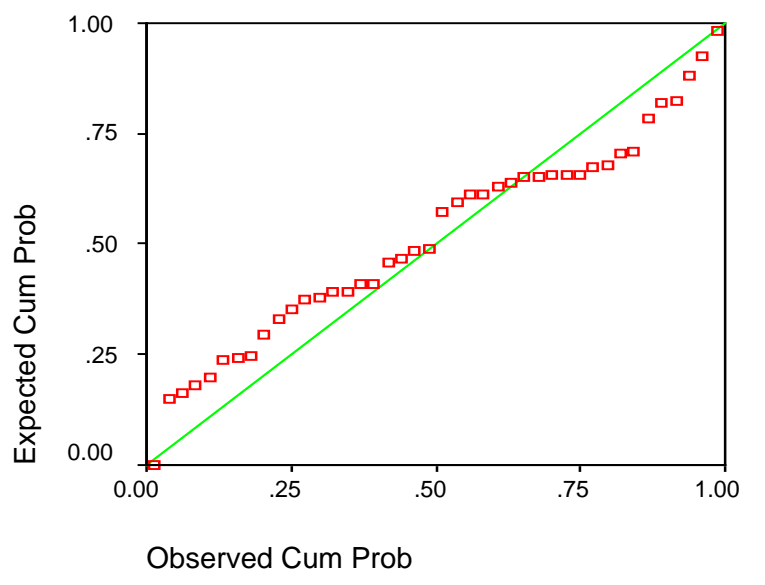


APPENDIX H: NORMALITY OF VOLUNTEER COST SAVINGS REGRESSION EQUATION 
The histogram below can be used to indicate the assumption of normality of the error term. Because the shape of the histogram follows the shape of the normal curve it can be determined that the normality is acceptable. There are few causes for concern in regards to outliers. Furthermore, the P-P plot follows the 45 degree line indicating that normality is acceptable.

Histogram

Dependent Variable: Volunteer Cost Savings

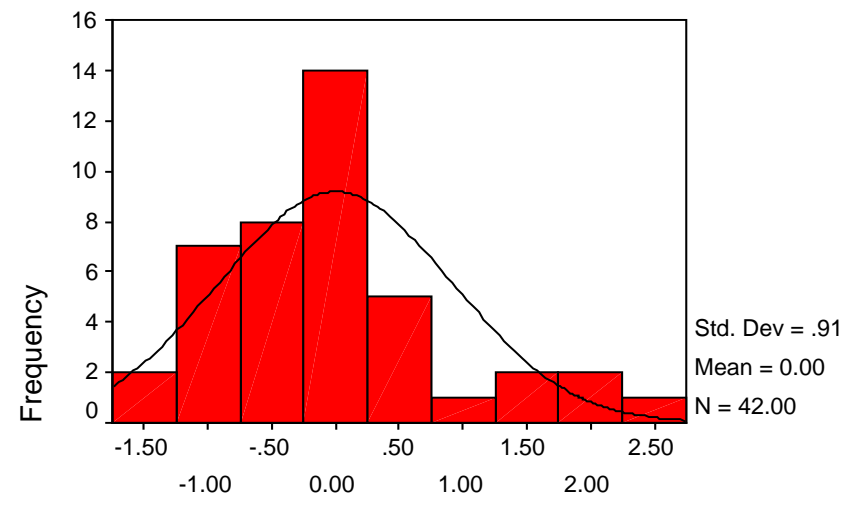

Regression Standardized Residual

Normal P-P Plot of Regression Standardized Residual

Dependent Variable: Volunteer Cost Savings

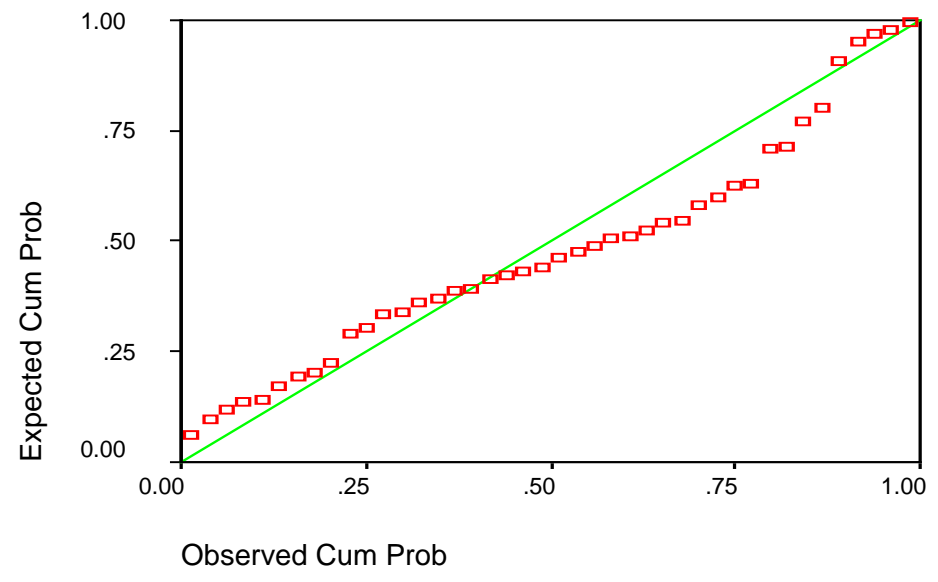




\section{APPENDIX I: NORMALITY OF PATIENT SATISFACTION REGRESSION EQUATION}


The histogram below can be used to indicate the assumption of normality of the error term. Because the shape of the histogram follows the shape of the normal curve it can be determined that the normality is acceptable. Furthermore, the P-P plot follows the 45 degree line indicating that normality is acceptable.

\section{Histogram}

Dependent Variable: Patient Satisfaction

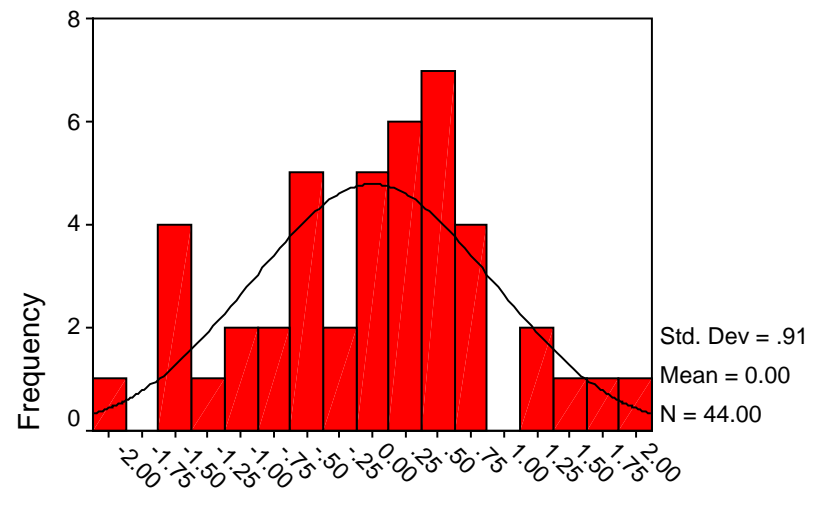

Regression Standardized Residual

Normal P-P Plot of Regression Standardized Residual

Dependent Variable: Patient Satisfaction

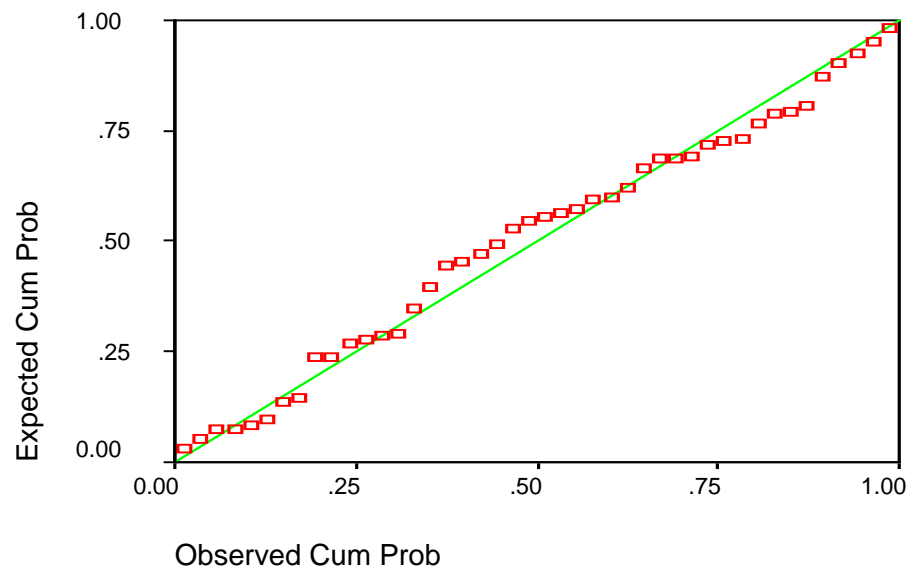




\section{APPENDIX J: IRB APPROVAL LETTER}




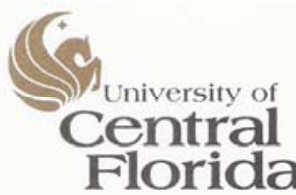

Office of Research \& Commercialization

December 1, 2006

Renee Brent, MSHSA, LHRM

Adjunct Instructor

Department of Health Professions

HPA2 210

Orlando, FL 32816-2205

Dear Ms. Brent:

As per our conversations and emails, the Institutional Review Board has determined that your proposed study, "Valuing Volunteers: The Impact of Volunteerism on Hospital

Performance," does not require Institutional Review Board (IRB) approval. The research does not fit the definition of human participant research, in that: the unit of analysis is the hospital.

Thank you for your time in resolving this issue.

Sincerely,

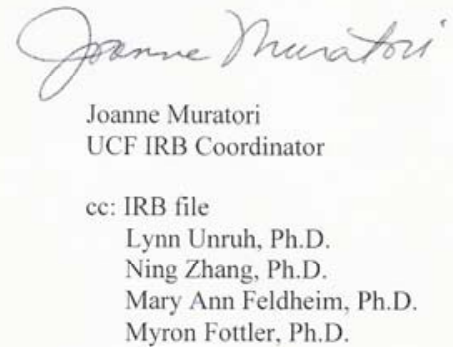

JM:jm

12201 Research Parkway • Suite 50I • Orlando, FL 32826-3246 • 407-823-3778 • Fax 407-823-3299 


\section{LIST OF REFERENCES}

Aiken, L.H., Clarke, S.P., Cheung, R.B., Sloane, D.M., and Silber, J.H. (2002). Hospital nurse staffing and patient mortality, nurse burnout, and job dissatisfaction. JAMA, 288, 19871993.

Akinci, F., and Krolikowski, D. (2005). Nurse staffing levels and quality of care in Northeastern Pennsylvania nursing homes. Applied Nursing Research 18, 130-137.

Allen, P. (October, 2006). Long Term Care Ombudsman Volunteers: Making a Measurable Difference for Nursing Home Residents. International Journal of Volunteer Administration, 24, (2), 5-14.

Baisden, H. (October 29, 2001). Hospital volunteers seen playing important roles when disaster strikes. AHA News, 37, (43), 1-3.

Blegen, M.A., and Vaughn, T. (1998). A multisite study of nurse staffing and patient occurrences. Nursing Economics, 16, 196-203.

Bostick, J.E. (2004). Relationship of nursing personnel and nursing home care quality. Journal of Nursing Care Quality 19, 130-136.

Christian, M.S. (June, 2007). Measuring the Output of Healthcare in the United States. Survey of Current Business, The Bureau of Economic Analysis, 78-83.

Conners, T.D. (1995). The Volunteer Management Handbook. John Wiley \& Sons, Inc., NY.

Donabedian, A. (2003). An Introduction to Quality Assurance in Health Care. Oxford University Press, NY.

Dordrecht, H. (1978). The economic nature and value of volunteer activity in Canada. Social Indicators Research 5, (1-4), 1-71. 
Downe-Wamboldt, B., and Ellerton, M. (Winter 1986). A Study of the Role of Hospice Volunteers. The Hospice Journal 1, (4), 17-31.

Ellis, S.J. (1999). The Dollar Value of Volunteer Time. Focus on Volunteering KopyKit, $2^{\text {nd }}$ ed. Energize, Inc.

Flood, A.B., Shortell, S.M., and Scott, W.R. (1997). Organizational Performance: Managing for Efficiency and Effectiveness. In S.M. Shortell, A.D. Kaluzny, Essentials of Health Care Management. Delmar Publishers, International, 382-398.

Florida Center for Health Information and Policy Analysis. (2007). Agency for Health Care Administration. Tallahassee, FL.

Fottler, M.D., and Malvey, D. (2003). Organized Delivery Systems. In L. Wolper, ed. HealthCare Administration: Planning, Implementing and Managing Organized Delivery Systems. Philadelphia, PA: Lippincott.

Gaskin, K. (n.d.). Valuing Volunteers in Europe: A Comparitive Study of the Volunteer Investment and Value Audit. London: Institute for Volunteering Research.

Gliner, J.A., and Morgan, G.A. (2000). Research Methods in Applied Settings: An Integrated Approach to Design and Analysis. Lawrence Erlbaum Associates, Inc., Mahwah, NJ.

Goulbourne, M., and Embuldeniya, D. (2002). Assigning Economic Value to Volunteer Activity: Eight Tools for Efficient Program Management. Toronto, Ontario: Canadian Centre for Philanthropy.

Govekar, P.L., and Govekar, M.A. (2002). Using Economic Theory and Research to Better Understand Volunteer Behavior. Nonprofit Management \& Leadership, 13, (1), 33-48.

Graff, L. (2001). Be Careful What We Wish For! The Cost-Benefit Analysis of Volunteering. Retrieved from the Web July 16, 2007. www.energizeinc.com 
Gussow, Z. (1989). Leprosy, Racism, and Public Health. Boulder, CO: Westview Press, Inc.

Handy, F., and Srinivasan, N. (December 2005). The Demand for Volunteer Labor: A Study of Hospital Volunteers. Nonprofit and Voluntary Sector Quarterly, 34, (4), 491-509.

Handy, F., and Srinivasan, N. (March 2004). Valuing Volunteers: An Economic Evaluation of the Net Benefits of Hospital Volunteers. Nonprofit and Voluntary Sector Quarterly, 33 (1), 28-54.

Help the Hospices. (2006). Valuing Volunteers. England: Help the Hospices.

Independent Sector. (November 2001). Giving and Volunteering in the United States. Washington, DC: Independent Sector.

Jones, H. (December 2004). Volunteering for Health. Wales Council for Voluntary Action. Welsh Assembly Government.

Jones Jr., R. L. (January/February 2002). The value of volunteers. Healthcare Executive, 17, (1), $66-67$.

Kentner, N. Lange, C., Reifschneider, E., and Takacs, A. (2003). The Cost and Benefits of Volunteers. Michigan: Michigan State University Extension.

Kovner, C., and Gergen, P.J. (1998). Nurse staffing levels and adverse events following surgery in US hospitals. Image Journal of Nursing Scholarship, 30, 315-321.

Lankshear, A.J., Sheldon, T.A., and Maynard, A. (2005). Nurse staffing and healthcare outcomes - A systematic review of the international research evidence. Advances in Nursing Science 28, 163-174.

Lake, E. T. (1999). The organization of hospital nursing. Unpublished Dissertation, University of Pennsylvania. 
Lake, E. T., and Friese, C.R. (2006). Variations in nursing practice environments - Relation to staffing and hospital characteristics. Nursing Research, 55, (1), 1-9.

Larson, L. (September 2004). Volunteers: Help in Plain Sight. Trustee, 57, (8), 6-11.

Maxwell, W.D. (1969). Production Theory and Cost Curves. Applied Economics, 1, 211-224.

Mook, L., Handy, F., and Quarter, J. (2007). Reporting Volunteer Labour at the Organizational Level: A Study of Canadian Nonprofits. Voluntas, 18 (55-71).

Needleman, J., Buerhaus, P.I., Stewart, M., Zelevinsky, K., and Mattke, S. (2006). Nurse staffing in hospitals: Is there a business case for quality? Health Affairs 25, 204-211.

Patient Safety Indicators Overview. (February 2006). AHRQ Quality Indicators. Rockville, MD: Agency for Healthcare Research and Quality. http://www.qualityindicators.ahrq.gov/psi_overview.htm

Penner, L.A. (2002). Dispositional and Organizational Influences on Sustained Volunteerism: An Interactionist Perspective. Journal of Social Issues, 58, (3), 447-467.

Pidgeon, Jr., W. P. (1998). The Universal Benefits of Volunteering: A Practical Workbook for Nonprofit Organizations, Volunteers, and Corporations. John Wiley \& Sons, Inc., NY.

Schmidt, L.A. (2004). Patients' perceptions of nurse staffing, nursing cars, adverse events, and overall satisfaction with the hospital experience. Nursing Economics 22, 295-306.

Silber, J.H., Rosenbaum, P., and Ross, R. (1995). Comparing the contributions of groups of predictors: which outcomes vary with hospital rather than patient characteristics. JASA 90, 7-18. 
Tourangeau, A.E., Giovannetti, P. Tu, J.V., and Wood, M. (2002). Nursing related determinants of 30 day mortality for hospitalized patients. Canadian Journal of Nursing Research 33, $71-88$.

Unruh, L. (2003). Licensed nurse staffing and adverse events in hospitals. Medical Care 41, 142152.

Volgistics. (2006). FTE. Retrieved August 20, 2006 from http://www.volgistics.com/ex /help.dll?ACT=18\&TOPIC=1036

Weech-Maldonado, R., Meret-Hanke, L., Neff, M.C., and Mor, V. (2004). Nurse staffing patterns and quality of care in nursing homes. Health Care Management Review 29, 107116.

Wells, B. L. DePue, J. D., Buehler, C. J., Lasatar, T. M., and Carleton, R. A. (Spring 1990). Characteristics of Volunteers Who Deliver Health Education and Promotion: A Comparison with Organization Members and Program Participants. Health Education Quarterly 17, (1), 23-35.

Wolford, S. (February 1995). Emergency Department Patient Liaison Volunteers: A Cost Containment and Visitor Satisfaction Strategy. Journal of Emergency Nursing 21, 17-21.

Wymer, Jr., W.W. (1999). Hospital Volunteers as Customers: Understanding Their Motives, How They Differ from Other Volunteers, and Correlates of Volunteer Intensity. In D.R. Self, W.W. Wymer (Ed.), Volunteerism Marketing: New Vistas for Nonprofit and Public Sector Management (Vol. 6, No. 2/3, pp 51-76). Haworth Press, NY.

Zweigenhaft, R. L., Armstrong, J., Quintis, F., and Riddick, A. (February 1996). The Motivations and Effectiveness of Hospital Volunteers. Journal of Social Psychology, $136,(1), 25-35$. 